7.6\% CZGSe Solar Cells Thanks to Optimized CdS Chemical Bath Deposition Peer-reviewed author version

Choubrac, Leo; BRAMMERTZ, Guy; Barreau, Nicolas; Arzel, Ludovic; Harel, Sylvie; MEURIS, Marc \& VERMANG, Bart (2018) 7.6\% CZGSe Solar Cells Thanks to Optimized CdS Chemical Bath Deposition. In: PHYSICA STATUS SOLIDI A-APPLICATIONS AND MATERIALS SCIENCE, 215(13) (Art No 1800043).

DOI: $10.1002 /$ pssa.201800043

Handle: http://hdl.handle.net/1942/27350 


\title{
WILEY-VCH
}

\section{6\% CZGSe solar cells thanks to optimized CdS chemical bath deposition}

L. Choubrac, G. Brammertz, N. Barreau, L. Arzel, S. Harel, M. Meuris and B. Vermang

\begin{abstract}
:
In this study, CdS chemical bath deposition has been investigated to improve the performance of thin film solar cell based on $\mathrm{Cu}_{2} \mathrm{ZnGeSe}_{4} / \mathrm{CdS}$ heterojunction. The influence of both the bath temperature and the dipping duration on the CdS thin film properties were explored thanks to the combination of scanning electron microscopy (SEM) and Raman spectroscopy, while the photovoltaic parameters of the resulting solar cells are discussed from currentvoltage (IV) and external quantum efficiency (EQE) measurements. The highest efficiency achieved herein (without antireflection coating), is $7.6 \%$. Although it represents 35\% relative improvement compared to previous best efficiency, this champion device is still limited by interface recombination. Different strategies are finally proposed to further increase the performance of these solar cells.
\end{abstract}

\section{Introduction}

Most of the recent studies aiming at increasing the tin-kesterite $\mathrm{Cu}_{2} \mathrm{ZnSn}(\mathrm{S}, \mathrm{Se})_{4}$ (CZTSSe)based solar cells performance rely on the successful use of germanium as a surface dopant, improving CZTSSe/CdS interface ${ }^{1}$; a similar effect is observed when few nanometres of germanium are supplied onto the back-contact prior to the absorber growth. The literature also reports lowered voltage-deficit when using mixed Ge-Sn kesterite material $\left(\mathrm{Cu}_{2} \mathrm{Zn}\left(\mathrm{Sn}_{1-}\right.\right.$ $\left.\left.{ }_{x} \mathrm{Ge}_{\mathrm{x}}\right)(\mathrm{S}, \mathrm{Se})_{4}\right)$ absorber layers ${ }^{2}$. All of these results suggest the presence of germanium favours the achievement of improved efficiency and one may expect further progress could be achieved by using $\mathrm{Cu}_{2} \mathrm{ZnGe}(\mathrm{S}, \mathrm{Se})_{4}$ (CZGSSe) material as absorber. In addition, the complete substitution of tin by germanium implies the widening of the semiconductor bandgap from 1 


\section{WILEY-VCH}

$1.35 \mathrm{eV}$ (for the pure selenide phase) up to $2.00 \mathrm{eV}$ (for the pure sulphide phase), which is 400 to $500 \mathrm{meV}$ wider than CZTSSe counterpart ${ }^{3-5}$ and makes CZGSSe-thin film valuable for top-cell absorber material in tandem devices.

However, to the best of our knowledge, the best efficiency reported so far using CZGSSe as absorber layer is $6.0 \%$ for the sulfo-selenide (CZGSSe) ${ }^{6}$ phase and $5.5 \%$ for the selenide (CZGSe) phase ${ }^{7}$, which is far from tin-kesterite or mixed (tin-germanium)-kesterite based solar cells (12.6\% and $12.3 \%$ respectively) ${ }^{8,9}$; these champion cell efficiencies were achieved with CBD-CdS buffer layer.

Since the absorber/CdS heterojunction characteristics rule the solar cell operation, a specific optimization of the CdS buffer layer for CZGSe absorber appears of major importance for the improvement of the device performance. The present work aims at optimizing the CdS-buffer chemical bath deposition (CBD) to identify and minimize the mechanisms limiting the efficiency at the CZGSe/CdS hetero-interface. The approach we followed consists of firstly determine both the surface and bulk properties of our CZGSe thin films. Secondly, the experimental conditions during the deposition of CdS are varied and the resulting CZGSe/CdS structures are investigated following an original method combining scanning electron microscopy and Raman spectroscopy. Finally, the related device characteristics are discussed based on CZGSe/CdS investigations.

\section{Experimental methods}

\subsection{Samples fabrication and labelling}

All solar cells were prepared from soda-lime glass (SLG)/Na-barrier/Mo/absorber stacks of $2.5 \times 5 \mathrm{~cm}^{2}$; the absorber layers were prepared by the IMEC, as described in Brammertz et al. ${ }^{10}$. All additional process steps were performed at the IMN: CdS n-type junction partner was firstly deposited by chemical bath deposition (CBD) in an aqueous bath with the following 


\section{WILEY-VCH}

chemicals concentrations: ammonia $[1 \mathrm{M}]$, cadmium acetate $[2.6 \mathrm{mM}]$ and thiourea $[0.1 \mathrm{M}]$. Reactants, reactor and samples are kept at room temperature, while a thermostatic bath is stabilized at the targeted temperature. The procedure for the CBD is as follows: reactants are poured into the reactor, then the samples are directly introduced into the latter; the chronometer starts immediately after the insertion of the reactor into the thermostatic bath. Because the (CBD)CdS process is highly critical and setup dependent, a scheme of the CdS deposition setup, as well as the evolution of reactants temperature for various thermostatic bath temperatures are presented in Figure 1.

An intrinsic $\mathrm{ZnO}(\approx 80 \mathrm{~nm})$ layer and aluminium-doped $\mathrm{ZnO}(\approx 200 \mathrm{~nm})$ layers were then sputtered onto the CZGSe/CdS structures. Ni/Al/Ni finger grids were finally deposited and cells of $0.5 \mathrm{~cm}^{2}$ designed by mechanical scribing (i.e. there are typically 16 "sister-cells" per experiment to ensure significant statistics).

Samples and solar cells are labelled "T-t" according to their CdS processing; T corresponds to the deposition bath temperature (in ${ }^{\circ} \mathrm{C}$ ) whereas $\mathrm{t}$ is the duration (in min) of samples immersion within the chemical reactor. As an example: 58-7 means the (CBD)CdS was prepared from the immersion of the reactor for 7 minutes into the thermostatic bath maintained at $58^{\circ} \mathrm{C}$.

\subsection{Material characterizations}

Scanning electron microscopy (SEM) observations were performed using a JEOL-7600 at an acceleration voltage of $5 \mathrm{kV}$, using secondary (SEI) or backscattered (BEI) modes. The absorber layer composition was determined by electron dispersive spectroscopy (EDS) using a JEOL-5800 SEM equipped with a germanium spectrometer PGT-IMIX, operating at an accelerating voltage of $15 \mathrm{kV}$. 


\section{WILEY-VCH}

X-ray diffraction patterns were collected with a Bruker D8-diffractometer in Bragg-Brentano geometry, using a Monochromatized $\mathrm{Cu}_{\mathrm{K}-\mathrm{L} 3}$ X-ray source (1.540598 $\AA$ ) and a LynxEye PSD detector. Spectra were collected in the $10-100^{\circ} 2 \theta$ range with $0.0084^{\circ}$ steps. Cells parameters were refined thanks to LeBail refinement using the JANA2006 software. ${ }^{11}$

Raman spectra were recorded using a Jobin-Yvon T64000 spectrometer in backscattering configuration and coupled with a microscope; a $514.5 \mathrm{~nm}$ excitation wavelength was used as excitation light. In addition, measurements with $458 \mathrm{~nm}$ and $785 \mathrm{~nm}$ excitation wavelengths were conducted using a Renishaw InVia Reflex spectrometer. For all excitation wavelengths the spectra were calibrated in frequency using the Si band at $520.5 \mathrm{~cm}^{-1}$; the spot size were in the range of 1 to $5 \mu \mathrm{m}^{2}$. Light power tests have been conducted to ensure there is no modification of the spectra (local heating effect) or material (order-disorder transition of the kesterite layer) induced by the laser beam ${ }^{12,13}$. The presented Raman intensity ratios are the average values from 5 spectra recorded from one sample. The latter ratio was calculated from a spectrum as first order CdS peak area $\left(\approx 300 \mathrm{~cm}^{-1}\right)$ over the sum two main CZGSe peaks $\left(\approx 176\right.$ and $\left.204 \mathrm{~cm}^{-1}\right)$ areas. An example of intensity ratio determination is given in the supporting information.

XPS: Absorber surface chemical compositions were determined by X-ray Photoemission Spectroscopy (XPS). Measurements were performed on an AXIS Ultra spectrometer using a monochromatic Al Ka X-ray source with $20 \mathrm{eV}$ pass energy. The analyzed area was 700x300 $\mu \mathrm{m}^{2}$. The Kratos charge neutralizer system was used during all the experiments. Surface composition of the absorber was derived from the intensities of $\mathrm{Zn} \mathrm{3p}, \mathrm{Cu} 3 \mathrm{p}, \mathrm{Ge} 3 \mathrm{~d}$ and Se 3d photoelectron peaks. These core levels were selected for their low binding energies and similar kinetic energies. In these conditions, the Information Depth (ID) of the different lines is comparable and the analyzed thickness is $\approx 10 \mathrm{~nm}$. 


\section{WILEY-VCH}

Photoluminescence spectra were acquired with a Hamamatsu C12132 time resolved photoluminescence tool. The sample was illuminated on a $3 \mathrm{~mm}^{2}$ area with a $15 \mathrm{kHz}$ pulsed YAG laser at $532 \mathrm{~nm}$ with an average power of $1 \mathrm{~mW}$. The photoluminescence signal was acquired in the time-correlated photon counting mode with a Si photomultiplier tube. The photoluminescence photon counts were normalized for the quantum efficiency of the system.

\subsection{Electrical characterizations}

Room temperature current-voltage $(\mathrm{J}(\mathrm{V}))$ characteristics were recorded using AM1.5G illumination source, normalized to $1000 \mathrm{~W} / \mathrm{m}^{2}$. To discuss the effect of illumination conditions on the J(V) curves, neutral filters and colour filter (610 nm, hereafter named "red filter”) have been used.

Room temperature external quantum efficiency (EQE) was measured thanks to a laboratorybuilt setup using a chopped light from grating-monochromated Xe-lamp source, Si and InGaAs reference cells were used for calibration.

\section{Results}

\subsection{Up to $7.6 \%$ CZGSe/CdS solar cell}

\subsubsection{Absorber layer characterizations}

The thickness of the absorber layers used for the present study is about $1.5 \mu \mathrm{m}$. Because of band tailing, the determination of the energy bandgap of kesterite thin film is rather complicated $^{14}$. Therefore, the energy band gap of CZGSe was evaluated from the linear extrapolation to zero of the EQE large wavelength cut-off. As shown in the Figure 7, the bandgap energy is $1.36 \mathrm{eV}$, which also corresponds to the maximum of the PL peak at room temperature.

SEM plane views of the surface, the peeled off back side as well as the cross section views of the absorber, presented in the Figure 2, show the layer is dense and composed of grains which width is about 300 to $1000 \mathrm{~nm}$. No secondary phase is observed by visual inspection using 5 


\section{WILEY-VCH}

BEI mode. The depth analysed by the EDS was estimated using the CASINO software ${ }^{15}$ to be about $850 \mathrm{~nm}$, which is close to one half of the absorber thickness. The composition of the analysed thickness from the surface corresponds to $[\mathrm{Cu}] /([\mathrm{Zn}]+[\mathrm{Ge}]) \approx 0.9$ and $[\mathrm{Zn}] /[\mathrm{Ge}] \approx$ 1.5 (that is slightly Cu-poor and significantly Zn-rich), whereas the analyses from the back side (peeled-off layers) demonstrate much closer to stoichiometry composition $[\mathrm{Cu}] /([\mathrm{Zn}]+[\mathrm{Ge}]) \approx 1.0$ and $[\mathrm{Zn}] /[\mathrm{Ge}] \approx 1.1$. These EDS results suggest the composition throughout the absorber layer varies; however, the EDS software we used to calculate these compositions assumes homogenously distributed elements, therefore, additional analyses were performed to evaluate whether the high concentration of $\mathrm{Zn}$ at the surface of the layer results from compositional fluctuations of CZGSe phases, or from an actual Zn-rich surface phase.

XRD reveals a good crystallization of the CZGSe phase in a tetragonal lattice, which is compatible with the structural models reported on the literature (kesterite or stannite). Refined cell parameters are $a=5.60879(2) \& c=11.0330(6) \AA$, the very moderate difference with already reported values ${ }^{16}$ being attributed to slightly different composition and/or strain. Moreover this refined value has to be considered as an average considering the horizontal compositional gradient. The presence of ZnSe in a very moderate amount is clear, (see supporting information).

Amongst the advantages offered by recording Raman spectra using different excitation wavelength is that the depth of material probed can be varied, as well as important sensitivity enhancement to some secondary phases thanks to resonant effect. For instance, by using 458 $\mathrm{nm}$ excitation allows detecting a weak signal of $\mathrm{ZnSe}^{17}$ at the surface of the absorber, whereas the backside analysis does not show such a signal (see Fig 3 and Fig 4). In contrast, Raman spectra recorded with 785 and $514 \mathrm{~nm}$ excitation only show peaks assignable to CZGSe phase 


\section{WILEY-VCH}

in a kesterite structure ${ }^{18}$, independently of the analysed side. As the intensity ratio of ZnSe against CZGSe peaks is not significantly varying from one analysed area to another, one can conclude that ZnSe likely forms a continuous layer at the absorber surface, at least over the laser spot size. The investigation of the Mo back contact after peeling the absorber off also revealed the presence of $\mathrm{MoSe}_{2}$ phase, which is formed at the Mo/absorber interface during the synthesis of the CZGSe. The composition of the absorber surface estimated by XPS corresponds to $[\mathrm{Zn}] /([\mathrm{Cu}]+[\mathrm{Zn}]+[\mathrm{Ge}]) \approx 0.7$, which also suggests significantly Zn-rich uppermost CZGSe surface. The experimental conditions used during these acquisitions result in an information depth shallower than $10 \mathrm{~nm}$, which corroborates the Raman spectroscopy conclusions that the ZnSe secondary phase segregated at the CZGSe surface is not thicker than few nanometres. To confirm this hypothesis, selected absorbers were etched in hot $\mathrm{HCl}$ solution (concentration $12 \mathrm{wt} \%$, temperature $80^{\circ} \mathrm{C}$, duration $20 \mathrm{~min}$ ) known to remove $\mathrm{ZnSe}$ phases, then analysed following the same procedure as the as-grown CZGSe layer. After HCltreatment, ZnSe is no more detected by Raman spectroscopy (see Figure 4) and XRD (see supporting information). This latter information confirms ZnSe secondary phase forms at the absorber surface rather than as inclusions in the bulk of the layer.

\subsubsection{Effect of CdS bath duration on solar cell performances}

Because the literature reports on the importance of tuning CdS buffer layer deposition to achieve high efficient solar cells ${ }^{19,20}$, a set of devices was firstly prepared with (CBD)CdS deposited at $52{ }^{\circ} \mathrm{C}$, for durations increasing from 3 through $11 \mathrm{~min}$. $\mathrm{V}_{\mathrm{OC}}-\mathrm{FF}$ maps and $\mathrm{EQE}$ spectra of representative solar cells are presented on Figure 5 and Figure 6.

The shortest (CBD)CdS deposition duration (3 min) leads to low efficiency, all photovoltaic parameters being affected. All of these parameters are observed to increase with the dipping duration, until reaching a plateau after $5 \mathrm{~min}$. This behaviour is attributed to improved 


\section{WILEY-VCH}

absorber coverage and to increased CdS thickness (see 3.2.2 - first and second stage of deposition). Therefore, one can consider that dipping the absorber for 5 minutes is enough to ensure it is fully covered by the CdS, which thickness is also sufficient to achieve an optimal junction quality. Increasing the dipping duration up to 7 min leads to a marginal loss in current density due to increased blue photons absorption by the CdS. The best performing solar cell $\left(0.5 \mathrm{~cm}^{2}\right)$ reported in the present paper was fabricated with (CBD)CdS ('52-5’), achieving 7.6 \% ( $\mathrm{V}_{\mathrm{OC}}=558 \mathrm{mV} ; \mathrm{J}_{\mathrm{SC}}=22.8 \mathrm{~mA} / \mathrm{cm}^{2}$ and $\left.\mathrm{FF}=60 \%\right)$ without antireflection coating. In contrast to what is usually observed in chalcogenide based thin film solar cells, the increase of (CBD)CdS deposition (> $7 \mathrm{~min}$ ) results in dramatic junction deterioration. Indeed, despite the $\mathrm{V}_{\mathrm{OC}}$ improvement, the FF drastically decreases (10 to 15 abs.\%), which in addition to current loss leads to decreased efficiency. Furthermore, room temperature J(V) characteristics of devices fabricated with CBD duration longer than 7 min exhibit red-kink (distorsion under red illumination) and important crossover (crossing of the dark and light $\mathrm{J}(\mathrm{V})$ curves). Although interpreting those phenomena is complex, it is extremely important to propose original models providing new bricks of understanding to finally benefit on the $\mathrm{V}_{\mathrm{OC}}$ boost without suffering of the drawbacks. The following sections of the paper are devoted to that aim.

\subsection{Investigation on CdS growth to determine the origin of the efficiency drop for long deposition}

A literature screening led us to explore two hypotheses possibly explaining that long CBD durations hinder the performance of Mo/CZGSe/CdS/ZnO-based solar cells. The first one relies on the effective increase of CdS thickness with the dipping duration. The second one deals with a possible change in the growth regime, which yields drastically modified physicochemical properties of the growing (CBD)CdS after a critical dipping duration. To attempt 


\section{WILEY-VCH}

evaluating the relevance of these two hypotheses, complementary investigations were performed changing both the temperature of the thermostatic bath and the dipping time. These two experimental parameters are indeed those empirically affecting (CBD)CdS both in terms of thickness and physico-chemical property.

\subsubsection{Impact of (CBD)CdS layer thickness}

The growth rate of (CBD)CdS is known highly dependent of the bath temperature. For instance, using similar experimental conditions as those herein used, Ortega-Borges et al. reported more than doubled growth rate at $55^{\circ} \mathrm{C}$ relative to $45^{\circ} \mathrm{C}^{21}$. Several sets of solar cells were thus fabricated with (CBD)CdS buffer layer, as follows.

i- Two sets with dipping duration corresponding to the plateau shown in Fig.6 (6 min), but changing the bath temperature (labelled 58-6 and 64-6),

ii- One set prepared from a doubled dip, namely two times 61-5 (labelled 61-10 in the following), which interest is obtaining very thick CdS layer without exceeding the critical deposition duration resulting in lowered FF.

The optical bandgap of (CBD)CdS being about $2.5 \mathrm{eV}$, one can qualitatively estimate its thickness from the EQE in the range [340 nm; $500 \mathrm{~nm}$ ]. Figure 8 plots the EQE of the best device for each of $i$ and ii sets. The EQE of 52-9 cell, having hindered FF, is also plotted as comparison. As expected, increasing the bath temperature yields thicker (CBD)CdS. Interestingly, as presented in the Table I, the photovoltaic parameters of the resulting cells appear independent of (CBD)CdS thickness, as long as the dipping duration does not exceed 6 min. This is particularly clear comparing 61-10 and 52-9 (CBD)CdS based devices. As a conclusion, the thickness of (CBD)CdS itself is not at the origin of the hindered junction quality and lowered FF.

\subsubsection{Change of CdS properties}




\section{WILEY-VCH}

The chemical bath deposition (CBD) of CdS from aqueous ammonia-thiourea solution for thin film photovoltaic application has been developed and widely investigated since late 1980’s. This deposition method leads to highly defected CdS layers, actually composed Cd and $\mathrm{S}$, but also $\mathrm{O}$ and $(\mathrm{OH}-)$; some authors also detected other impurities such as $\mathrm{Si}, \mathrm{C}$ or $\mathrm{N}^{22-24}$ Moreover, the grains of CdS thin films can be either cubic or hexagonal; the coexistence of both crystal structures is usually detected in CBD processed layers ${ }^{25}$. The overall composition as well as the dominating crystal structure of the layer strongly affects the physic-chemical properties (namely the bandgap, absorption spectra, carrier concentration,...) of $\mathrm{CdS}^{26,27}$, thus the device optoelectronic characteristics. Focusing on studies using similar growth conditions as those used herein (namely temperature and precursors concentration), the (CBD) CdS growth can be divided into three regimes ${ }^{28,29}$, as described below:

Firstly, an "induction/coalescence" regime, associated to the nucleation/coalescence mechanism of the layer, which consists in the adsorption of $\mathrm{Cd}(\mathrm{OH})_{2}$ onto the surface of the substrate. The duration of this stage is strongly dependent on the chemical and morphological properties of the substrate.

Secondly, the CdS growth is majority driven by the interactions of individual atoms, called “ion-ion deposition”, with a fairly constant growth rate and resulting in a compact and dense layer. Simultaneously, colloids are formed in the solution; however, colloids-substrate repulsion is high enough to prevent colloids deposition.

Finally, after a critical duration, the solution is no more stable and colloids-substrate repulsion quenches. This leads to the third regime called “cluster by cluster deposition”, which results in a porous CdS layer topping the dense one grown when the "ion-ion" mechanism did dominate the deposition. The growth rate during this cluster-cluster regime is usually reported as very low, but there are some contradictions in the literature. 


\section{WILEY-VCH}

It is worth noticing that ion-ion and cluster-cluster growth mechanism yield CdS material with different properties (composition, defects nature and concentration, structure ...).

This drastic change in CdS physico-chemical characteristics has at least two major consequences on the solar cell operation, (i) all modifications in defects concentration directly impacts the carrier density of the CdS, also changing the potential distribution in the near junction area, and (ii) all changes in CdS physico-chemical properties imply modifications in the energy band structure at both the absorber/CdS and the CdS/ZnO interfaces.

To evaluate if this 3-regime model is applicable to CZGSe/(CBD)CdS in our experimental conditions, all of the samples were studied following an original approach combining SEM observations and Raman spectroscopy. The thickness of CdS was estimated from Raman spectra recorded on complete cells $\left(\lambda_{\text {exc }}=514 \mathrm{~nm}\right)$ and the intensity of the fitted peaks plotted as a function of dipping time. Since the excitation wavelength is $514 \mathrm{~nm}$, it will not be absorbed by the wide gap $\mathrm{ZnO} / \mathrm{ZnO}$ :Al window but will interact exclusively with the CdS buffer and the CZGSe absorber. This latter can be considered as infinite since this laser wavelength penetration depth into the absorber is about $80 \mathrm{~nm}$. Accordingly, the ratio between the intensity of Raman peaks attributed to CdS and CZGSe (i.e. $\mathrm{I}_{\mathrm{CdS}} / \mathrm{I}_{\mathrm{CZGSe}}$ ) can be considered as proportional to CdS thickness (See Fig. 10). Fig.9 depicts the SEM plane views of CZGSe/CdS taken prior to window and grids deposition in the case of 52-t and 64-t; nevertheless, the following discussion will be based on the data recorded on 52-t structures. Further information about the calculations of the ratio is presented in the supporting information. 


\section{WILEY-VCH}

First and second deposition regimes

The SEM observation (see Fig.9) reveals some deposition for dipping duration as short as 1.5 min. Indeed, at this stage, grains of few nm are clearly visible but the absorber surface is not fully covered. No drastic changes are observed after $3 \mathrm{~min}$; the absorber layer appears fully covered by the (CBD)CdS only after $6 \mathrm{~min}$, the CdS grains size remaining narrower than 10 nm. Regarding the evolution of CdS Raman signal versus dipping duration, CdS starts being detected only for $3 \mathrm{~min}$. The fact that no CdS structure is formed despite the absorber appears covered is not contradictory. Indeed, the induction/coalescence regime consists in the adsorption of Cd-based compounds, but not in the formation of CdS. After $3 \mathrm{~min}$, the formation of CdS is clearly attested by Raman and the growth rate appears constant until 7 min. This regime corresponds to ion-ion growth and a linear extrapolation of the Raman peak ratio to zero suggests it starts after 2 to $2.5 \mathrm{~min}$.

\section{Third regime of deposition}

When the dipping duration exceeds $7 \mathrm{~min}$, the SEM micrographs reveal the presence of larger clusters (about $100 \mathrm{~nm}$ ), consisting of an agglomerate of narrower clusters (typically $<10 \mathrm{~nm}$ ). These large clusters are even visible as yellow spots through optical microscope and consist of pure CdS phase (see supporting information). One should notice that the Raman signal ratios presented in the Fig.10 were recorded on areas free of those yellow spots. Fig.10 also show that the CdS growth rate drops after 7 min, suggesting a change of (CBD)CdS growth regime. This information corroborates that the critical duration for the transition from ion-ion towards cluster-cluster regimes occurs at about 7 min for the 52-t samples.

The three-regime growth mechanism being confirmed for the CZGSe/(CBD)CdS, one can now correlate the evolution of cells performance with the (CBD)CdS dipping duration as presented in Fig. 11. 


\section{WILEY-VCH}

\subsubsection{Influence of bath temperature and reliability}

In order to investigate on the role of both the temperature and the CdS deposition duration, a total of 31 batches of solar cells (about 400 working devices) have been prepared with similar absorber but different (CBD)CdS bath temperature $\left(52^{\circ} \mathrm{C}\right.$ through $\left.64^{\circ} \mathrm{C}\right)$ and dipping duration (1 through $11 \mathrm{~min}$ ). Increasing the bath temperature is known to enhance (CBD)CdS growth rates and probably influence the kinetic of regime transitions. In order to evaluate so, the combination of SEM and Raman was also implemented here. As shown in Fig.10, the duration to observe the transition from the induction- towards the ion-ion- regime appears independent of the bath temperature; this latter observation can easily be explained by the evolution of the actual temperature of the reactants shown in Fig.1. In contrast, once the ionion regime is reached, the growth rate increases with the temperature of the bath; increasing the bath temperature from $52{ }^{\circ} \mathrm{C}$ to $64{ }^{\circ} \mathrm{C}$ multiplies by 3 the growth rate within this regime. As a consequence, the cluster-cluster regime shifts earlier as the temperature increases, typically 7 min at $52{ }^{\circ} \mathrm{C}$ against 5 minutes at $64{ }^{\circ} \mathrm{C}$. These transitions are also clearly visible on the SEM images depicted in Fig.9. These observations suggest that the duration of the ionion regime becomes shorter as the temperature of the bath increases, which has a major impact on the reliability of the CBD process for the achievement of high efficiency CZGSe/(CBD)CdS based solar cells. Indeed, Figure 13 plots FF-V $V_{\text {OC }}$ parameters for (CBD)CdS growth corresponding to 58-t and 64-t and shows that whatever the bath temperature, the hindering of FF is concomitant with the transition from the ion-ion to clustercluster regime. As a consequence, to achieve the optimal performance of cells based on CZGSe/(CBD)CdS hetero-junction, the buffer growth has to be interrupted when the whole absorber is sufficiently covered and before the cluster-cluster regime starts. The tolerance to the dipping duration is thus increased when the bath temperature is lowered. 


\section{WILEY-VCH}

\section{Discussions}

\subsection{Modification of electrical properties when cluster deposition starts}

Major changes in the photovoltaic parameters are observed right after the transition from ionion to cluster-cluster regime. The most obvious are the moderate $\mathrm{V}_{\mathrm{OC}}$ increase and the important FF drop. J(V) curves were recorded under various illumination conditions to better understand the optoelectronic behaviour of the devices. As plotted in Fig. 12, after the clustercluster regime is reached, the crossover between dark and light $\mathrm{J}(\mathrm{V})$ curves is enhanced and the $\mathrm{J}(\mathrm{V})$ characteristics under red-light illumination are S-shaped (i.e. so-called red-kink). These observations indicate that the presence of CdS clusters detrimentally influences the operation of the device ${ }^{20}$. The red-kink, as well as cross-over, is likely to originate from photo-activated defects influencing the potential distribution throughout the pn-junction. If the clusters prevent their beneficial photo-activation, or create a detrimental ion-ionCdS/clustered-CdS interface, then the voltage across the device is differently distributed and the $\mathrm{J}(\mathrm{V})$ curves are no more those expected by a single diode model.

\subsection{What limit efficiency and suggestions of future work}

Several cells of $>7 \%$ efficiency have been obtained and exhibit similar electrical properties: The collection properties, especially the collection length (almost no drop of EQE as photon wavelength increases - Figure 5) are very promising, and considering the important $\mathrm{V}_{\mathrm{OC}^{-}}$ deficit, the FF is satisfying. The main limitation of the efficiency is an important $\mathrm{V}_{\mathrm{OC}}$ deficit (50\% of theoretical achievable $\mathrm{V}_{\mathrm{OC}}$ for this bandgap according to the Shockely Queisser limit). For comparison, low $\mathrm{V}_{\mathrm{OC}}$-deficit kesterite typically achieve $60 \%$ of the Shockely Queisser maximum $\mathrm{V}_{\mathrm{OC}}{ }^{30}$. Literature reports two main sources of $\mathrm{V}_{\mathrm{OC}}$-deficit for kesterite 


\section{WILEY-VCH}

solar cells ${ }^{31}$ : the first is an absorber-related limitation due severe band tailing and the second is interface recombination. The exact origin of this band tailing is still under discussion but is today widely reported to be caused, at least partly, by disorder in the $\mathrm{Cu}-\mathrm{Zn}$ kesterite lattice $(2 c-2 d \text { plan })^{32}$. Gershon et al. ${ }^{33}$ recently reported that a way to estimate band tailing is to calculate the energy difference between $(\mathrm{dQe} / \mathrm{d} \lambda)$ and the maximum photoluminescence emission peak. For high-efficient kesterite, this value appears to be in the range of 70-110 $\mathrm{meV}^{32,34,35}$. As for the CZGSe/ CdS prepared for this work this shift is only $60 \mathrm{meV}$ (Figure 7), we cannot attribute a specifically important bandtailing to the high $\mathrm{V}_{\text {OC}}$-deficit. Then, interface recombination is considered to be the main source of the $\mathrm{V}_{\mathrm{OC}}$-deficit observed here, an obvious potential origin of it being the presence of ZnSe at this interface. Another potential source of such interface recombination is an inadequate conduction band offset (CBO) between the absorber and the buffer. We didn't found CZGSe/CdS CBO measurement on the literature, but we can roughly estimate it: Crovetto et al compiled data present on the literature for CZTSe/CdS: $0.3<\mathrm{CBO}<0.6 \mathrm{eV}^{36}$ and Shu et al calculated CZGSe and CZTSe valence band minimum (VBM) to be very similar (0.03 eV difference $)^{37}$. As we determined CZGSe and CZTSe bandgap to be $\approx 1.36 \mathrm{eV}$ and $0.95 \mathrm{eV}$ respectively, CZGSe/CdS CBO is between 0.1 and $+0.2 \mathrm{eV}$. As we cannot determine whether CZGSe/CdS CBO is "cliff-like” or "spikelike”, it prevents us to conclude about a CBO-origin of the interface recombination. Moreover, a convincing discussion on the role of $\mathrm{CBO}$ has to take into account the presence of ZnSe at CZGSe/CdS interface, which is a hard topic as nor ZnSe thickness neither ZnSe CBO relatively to CZGSe and CdS are known.

Then, two strategies can be envisioned to improve CZGSe based solar cell efficiencies via interface recombination suppression: 1- preparation of ZnSe-free absorber layer (by etching or 


\section{WILEY-VCH}

modification of the process) 2- determination of actual CZGSe/CdS CBO to confirm CdS to be a suitable buffer layer material or suggest alternatives.

\section{Conclusion and perspectives}

In this work, the influence of CdS deposition parameters for CZGSe/CdS based solar cell was investigated. Combining SEM observations and Raman spectroscopy we show CdS deposition to be composed on 3 different steps, corresponding to different growth mechanisms. While there is almost no deposition of CdS during the first step, the properties of the CdS deposited during the second are satisfying. The CdS deposited during the third stage has less favorable optoelectronic properties, lowering solar cell efficiency. Low temperature CdS deposition is preferred as it delays beginning of the third stage, making longer the time slot leading to optimized CdS (completely covering and thick enough). A significant output of this CdS deposition optimization is the improvement of solar cell efficiency up to $7.6 \%$ without ARC, a relative 35\% improvement compared to previously highest reported value for CZGSSe solar cell. The efficiency is primary limited by an important $\mathrm{V}_{\text {OC }}$ deficit, mostly resulting from interface recombination. One can expect this issue to be solved or reduced by etching of the secondary phase observed at the surface (ZnSe), tuning again CdS buffer layer nature thanks to change of precursors, or using alternative material as buffer layer.

\section{References}

[1] S. Giraldo, T. Thersleff, G. Larramona, M. Neuschitzer, P. Pistor, K. Leifer, A. PérezRodríguez, C. Moisan, G. Dennler, and E. Saucedo, Prog. Photovolt. Res. Appl. 2016, 24, 1359.

[2] A.D. Collord and H.W. Hillhouse, Chem. Mater. 2016, 28, 2067.

[3] L. Huang, H. Deng, J. He, X. Meng, J. Tao, H. Cao, L. Sun, P. Yang, and J. Chu, Mater. Lett. 2015, 159, 1.

[4] D.B. Khadka and J. Kim, CrystEngComm 2013, 15, 10500.

[5] Q. Guo, G.M. Ford, W.-C. Yang, C.J. Hages, H.W. Hillhouse, and R. Agrawal, Sol. Energy Mater. Sol. Cells 2012, 105, 132. 


\section{WILEY-VCH}

[6] T. Schnabel, M. Seboui, A. Bauer, L. Choubrac, L. Arzel, S. Harel, N. Barreau, and E. Ahlswede, RSC Adv. 2017, 7, 40105.

[7] S. Sahayaraj, G. Brammertz, B. Vermang, T. Schnabel, E. Ahlswede, Z. Huang, S. Ranjbar, M. Meuris, J. Vleugels, and J. Poortmans, Sol. Energy Mater. Sol. Cells 2017, 171, 136.

[8] P.D. Antunez, D.M. Bishop, Y. Luo, and R. Haight, Nat. Energy 2017, 2, 884.

[9] W. Wang, M.T. Winkler, O. Gunawan, T. Gokmen, T.K. Todorov, Y. Zhu, and D.B. Mitzi, Adv. Energy Mater. 2014, 4, n/a.

[10] Guy Brammertz, Bart Vermang, Marc Meuris, and J Poortmans, n.d.

[11] Václav Petříček, Michal Dušek, and Lukáš Palatinus, Z. Für Krist. - Cryst. Mater. 2014, 229, 345.

[12] J.J.S. Scragg, L. Choubrac, A. Lafond, T. Ericson, and C. Platzer-Björkman, Appl. Phys. Lett. 2014, 104, 041911.

[13] M.Y. Valakh, V.M. Dzhagan, I.S. Babichuk, X. Fontane, A. Perez-Rodriquez, and S. Schorr, JETP Lett. 2013, 98, 255.

[14] S. Siebentritt, G. Rey, A. Finger, D. Regesch, J. Sendler, T.P. Weiss, and T. Bertram, Sol. Energy Mater. Sol. Cells 2016, 158, 126.

[15] H. Demers, N. Poirier-Demers, A.R. Couture, D. Joly, M. Guilmain, N. de Jonge, and D. Drouin, Scanning 2011, 33, 135.

[16] D.B. Khadka and J. Kim, J. Phys. Chem. C 2015, 119, 1706.

[17] S. López-Marino, Y. Sánchez, M. Placidi, A. Fairbrother, M. Espindola-Rodríguez, X. Fontané, V. Izquierdo-Roca, J. López-García, L. Calvo-Barrio, A. Pérez-Rodríguez, and E. Saucedo, Chem. - Eur. J. 2013, 19, 14814.

[18] M. Guc, S. Levcenko, V. Izquierdo-Roca, X. Fontané, E. Arushanov, and A. PérezRodríguez, J. Appl. Phys. 2013, 114, 193514.

[19] M.A. Contreras, M.J. Romero, B. To, F. Hasoon, R. Noufi, S. Ward, and K. Ramanathan, Thin Solid Films 2002, 403-404, 204.

[20] M. Neuschitzer, Y. Sanchez, S. López-Marino, H. Xie, A. Fairbrother, M. Placidi, S. Haass, V. Izquierdo-Roca, A. Perez-Rodriguez, and E. Saucedo, Prog. Photovolt. Res. Appl. 2015, 23, 1660.

[21] R. Ortega-Borges and D. Lincot, J. Electrochem. Soc. 1993, 140, 3464.

[22] A. Kylner, A. Rockett, and L. Stolt, Solid State Phenom. 1996, 51-52, 533.

[23] A. Kylner, J. Lindgren, and L. Stolt, J. Electrochem. Soc. 1996, 143, 2662.

[24] A. Kylner, J. Appl. Phys. 1999, 85, 6858.

[25] H. Khallaf, I.O. Oladeji, G. Chai, and L. Chow, Thin Solid Films 2008, 516, 7306.

[26] L. Zhou, X. Hu, and S. Wu, Surf. Coat. Technol. 2013, 228, S171.

[27] S. Mahanty, D. Basak, F. Rueda, and M. Leon, J. Electron. Mater. 1999, 28, 559.

[28] D. Lincot and R.O. Borges, J. Electrochem. Soc. 1992, 139, 1880.

[29] D. Lincot and J. Vedel, in Tenth EC Photovolt. Sol. Energy Conf. (Springer, Dordrecht, 1991), pp. 931-934.

[30] S. Bourdais, C. Choné, B. Delatouche, A. Jacob, G. Larramona, C. Moisan, A. Lafond, F. Donatini, G. Rey, S. Siebentritt, A. Walsh, and G. Dennler, Adv. Energy Mater. 2016, 6, n/a. [31] A. Polizzotti, I. L. Repins, R. Noufi, S.-H. Wei, and D. B. Mitzi, Energy Environ. Sci. 2013, 6, 3171.

[32] T. Gokmen, O. Gunawan, T.K. Todorov, and D.B. Mitzi, Appl. Phys. Lett. 2013, 103, 103506.

[33] T. Gershon, D. Bishop, P. Antunez, S. Singh, K.W. Brew, Y.S. Lee, O. Gunawan, T. Gokmen, T. Todorov, and R. Haight, Curr. Opin. Green Sustain. Chem. 2017, 4, 29. 


\section{WILEY-VCH}

[34] S.G. Haass, M. Diethelm, M. Werner, B. Bissig, Y.E. Romanyuk, and A.N. Tiwari, Adv. Energy Mater. 2015, 5, n/a.

[35] T.K. Todorov, J. Tang, S. Bag, O. Gunawan, T. Gokmen, Y. Zhu, and D.B. Mitzi, Adv. Energy Mater. 2013, 3, 34.

[36] A. Crovetto and O. Hansen, Sol. Energy Mater. Sol. Cells 2017, 169, 177.

[37] Q. Shu, J.-H. Yang, S. Chen, B. Huang, H. Xiang, X.-G. Gong, and S.-H. Wei, Phys. Rev. B 2013, 87, 115208.

Acknowledgment : This project has received funding from the European Union's Horizon 2020 research and innovation program under grant agreement No 640868 


\section{WILEY-VCH}
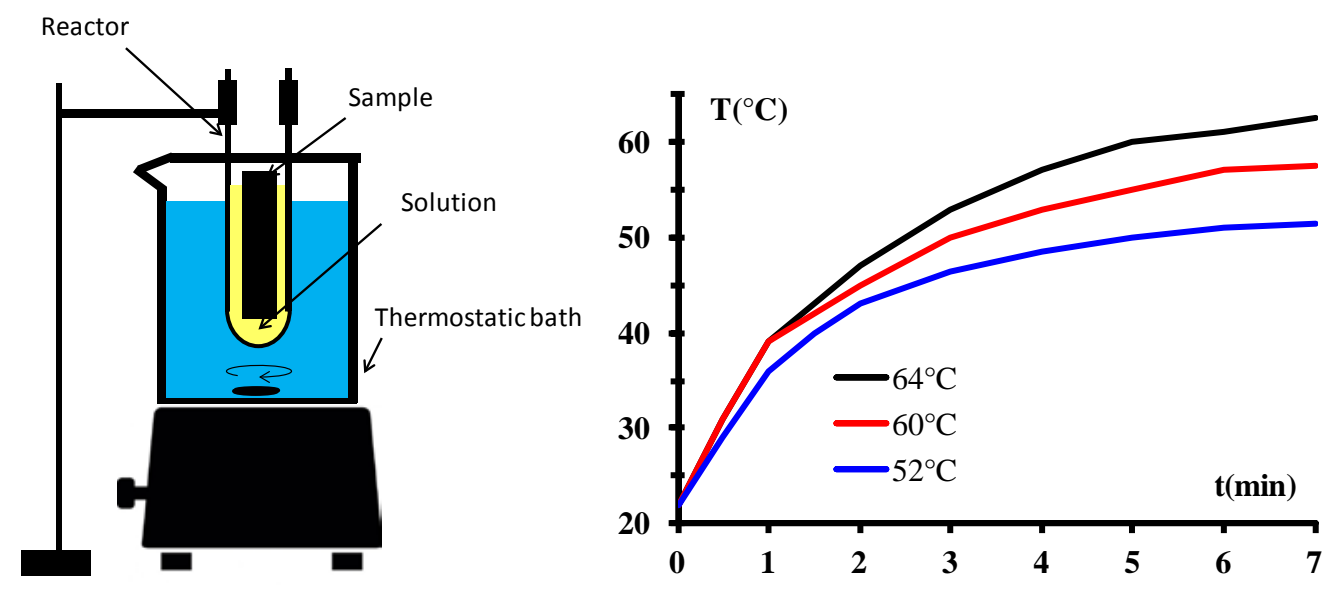

Figure 1. (left): Scheme of CdS deposition setup. (right): Time evolution of reactants temperature in the reactor, measured by replacing the sample by a thermocouple; for thermostated bath at 52,60 and $64^{\circ} \mathrm{C}$
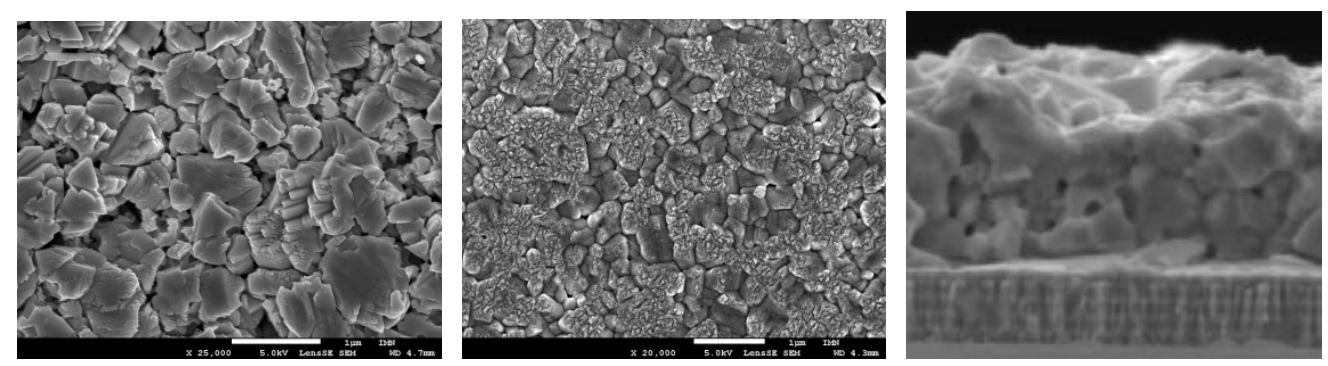

Figure 2. Surface (left), backside (center) and cross section (right) SEM micrographs of the absorber layer. Echelle de la cross section?

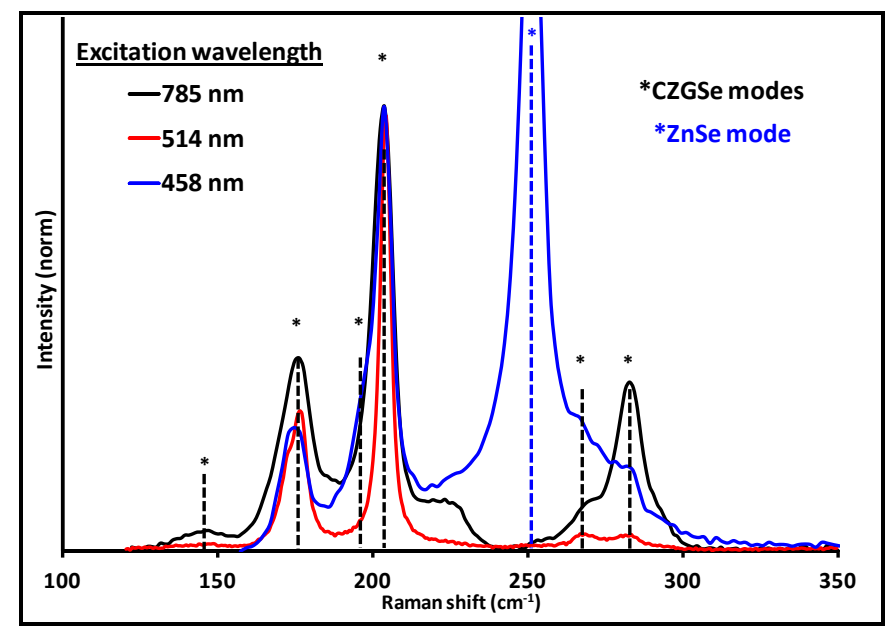

Figure 3. Raman spectra of bare absorber surface recorded using different excitation wavelength. Only CZGSe phase can be identified with 514 and $785 \mathrm{~nm}$ excitations, whereas $458 \mathrm{~nm}$ reveals the presence of $\mathrm{ZnSe}$. 


\section{WILEY-VCH}

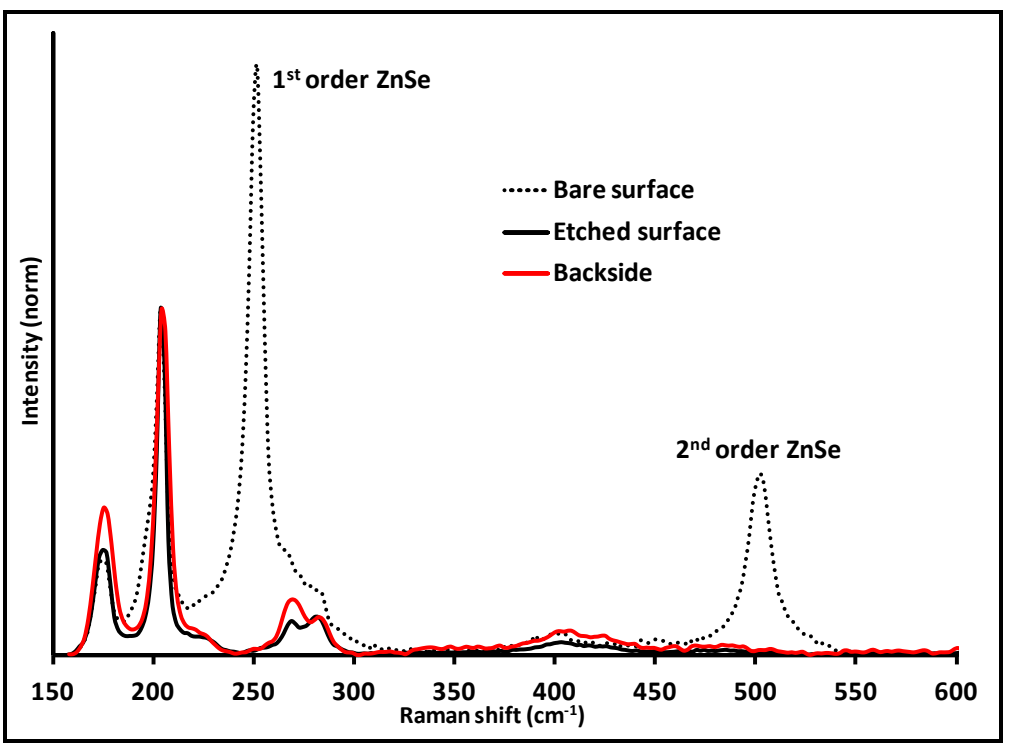

Figure 4. Raman spectra of absorber recorded using a 458nm excitation wavelength. Bare surface contains ZnSe, while only CZGSe is identified at backside and etched surface.

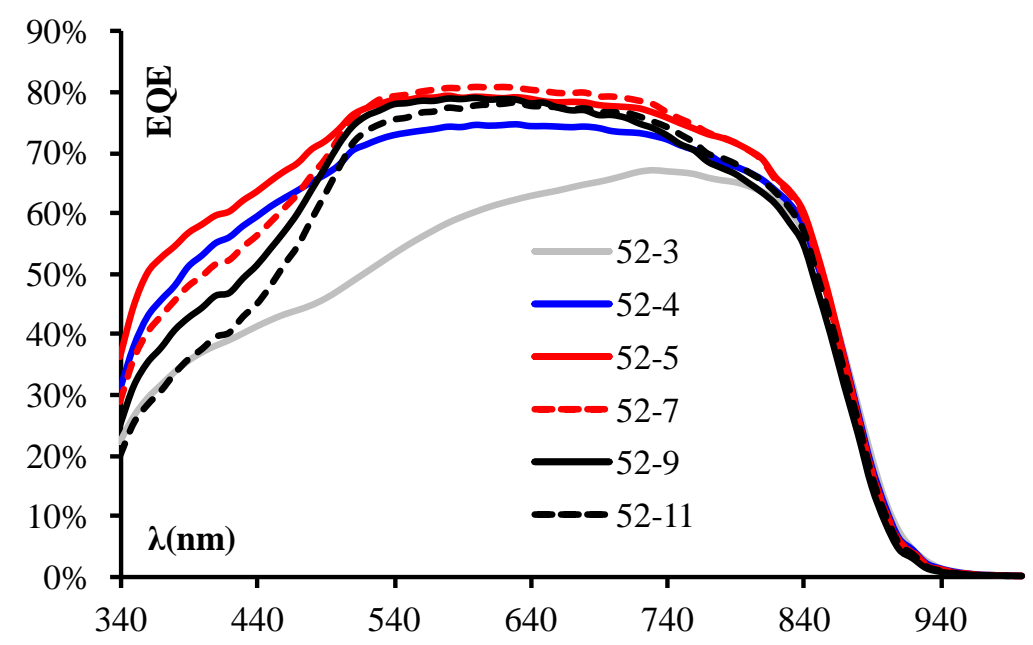

Figure 5. EQE spectra of solar cells prepared with CdS deposited at $52^{\circ} \mathrm{C}$ during various duration 


\section{WILEY-VCH}

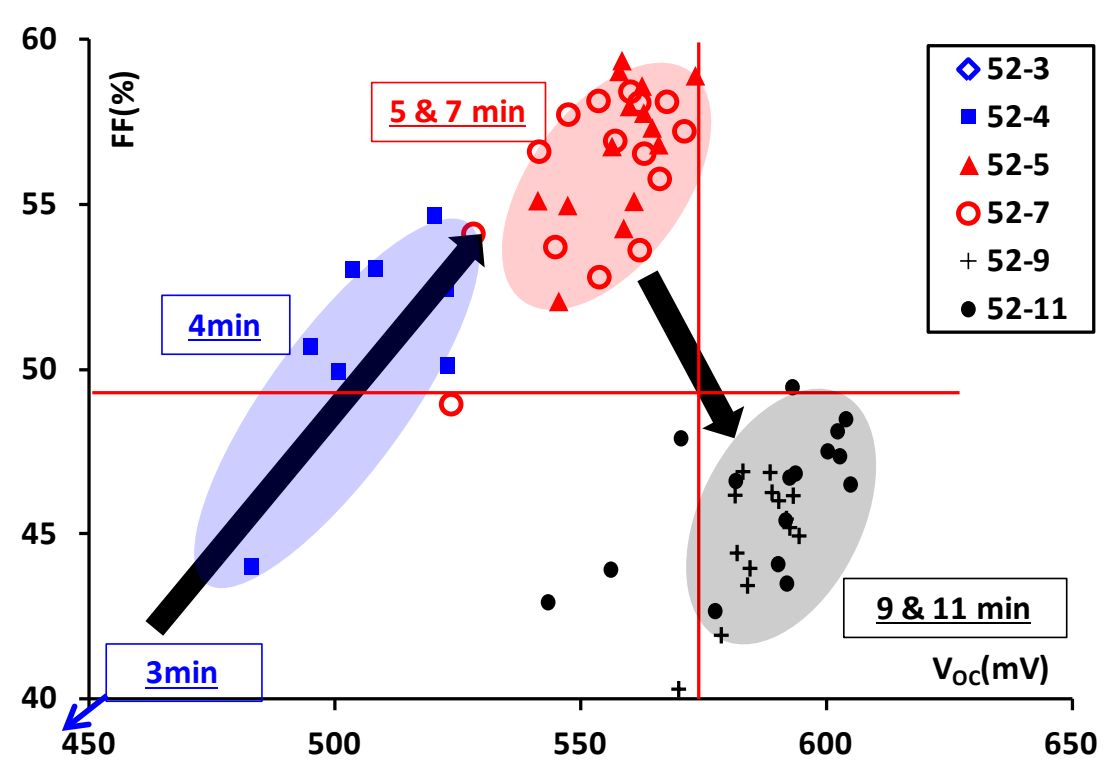

Figure 6. FF vs $\mathrm{V}_{\mathrm{OC}}$ map for $\mathrm{CdS}$ deposition at $52^{\circ} \mathrm{C}$ during various durations. Each point represents an individual solar cell. Cells prepared with a 3min CdS have too low FF and $\mathrm{V}_{\mathrm{OC}}$ values to be represented on this figure.
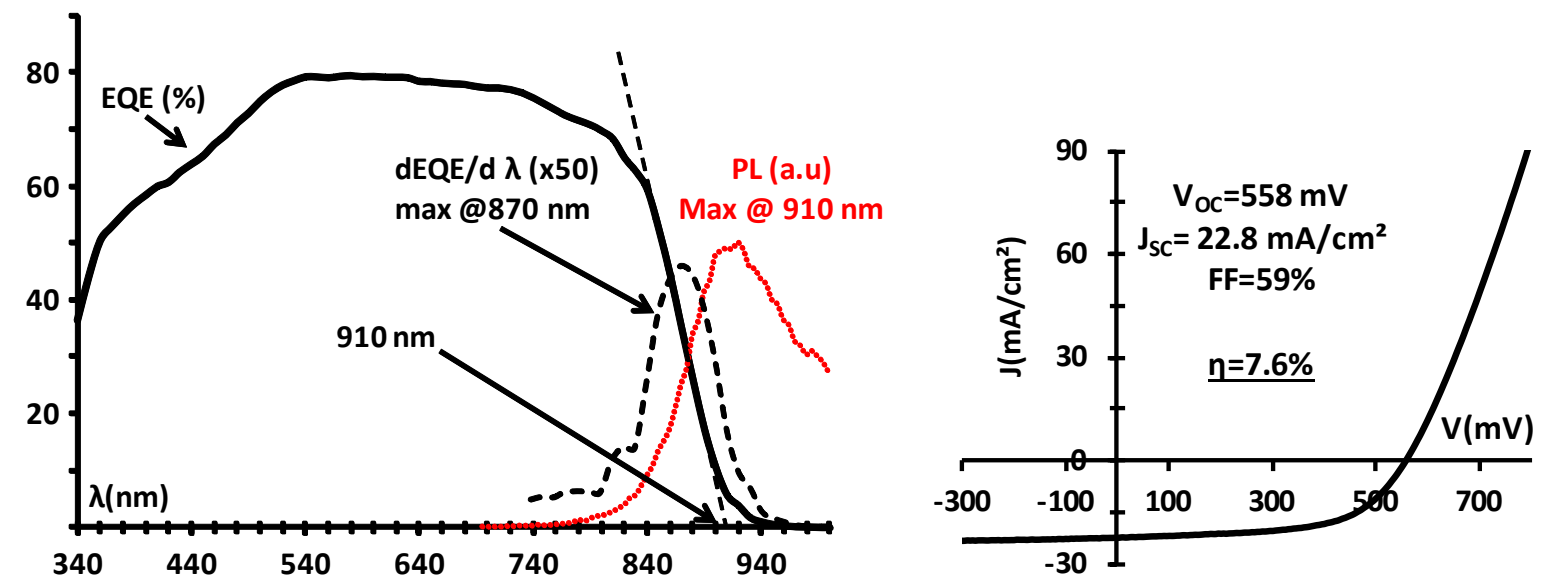

Figure 7: EQE (left) and J-V (right) of a 7.6\% efficient CZGSe/CdS solar cell 


\section{WILEY-VCH}

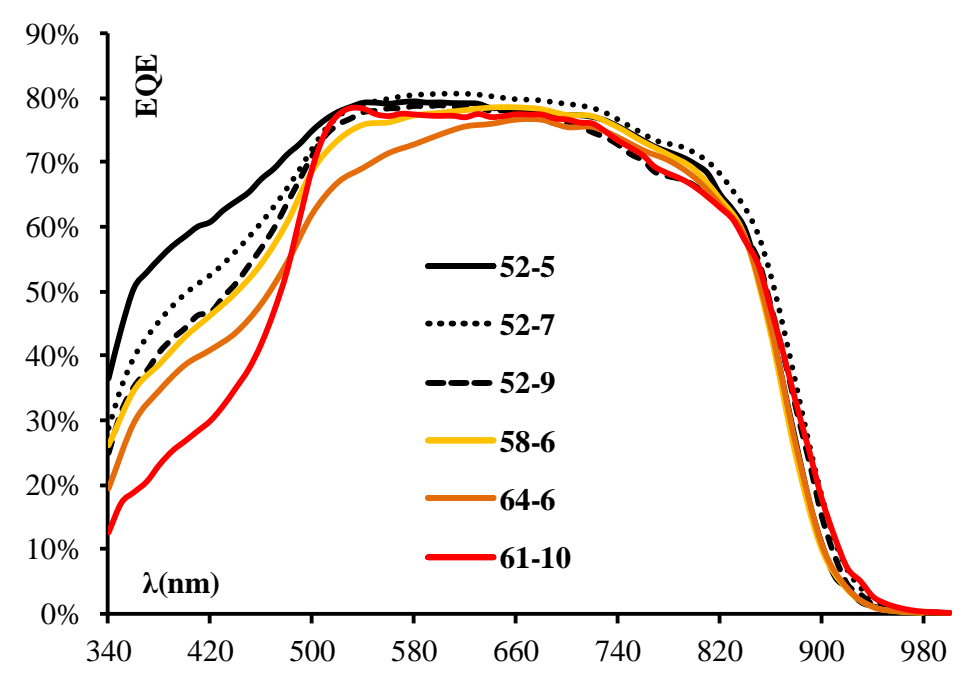

Figure 8. EQE spectra of solar cells prepared with various CdS buffer layer thicknesses.

Table 1. Electrical parameters of highest efficient solar cell of each batch.

\begin{tabular}{llllll}
\hline $\begin{array}{l}\text { CdS } \\
\text { deposition } \\
\text { temperature } \\
{\left[{ }^{\circ} \mathrm{C}\right]}\end{array}$ & $\begin{array}{l}\text { CdS } \\
\text { deposition } \\
\text { duration } \\
{[\mathrm{min}]}\end{array}$ & $\begin{array}{l}\mathrm{V}_{\mathrm{OC}} \\
{[\mathrm{mV}]}\end{array}$ & $\mathrm{FF}[\%]$ & $\begin{array}{l}\mathrm{J}_{\mathrm{SC}}{ }^{\mathrm{a})} \\
{\left[\mathrm{mA} / \mathrm{cm}^{2}\right]}\end{array}$ & $\begin{array}{l}\eta[\%] \\
52\end{array}$ \\
\hline 5 & 558 & 60 & 22.8 & 7.6 \\
58 & 6 & 538 & 60 & 21.7 & 7.0 \\
64 & 6 & 543 & 61 & 21.1 & 7.0 \\
61 & $10^{\mathrm{b})}$ & 547 & 57 & 20.7 & 6.5
\end{tabular}

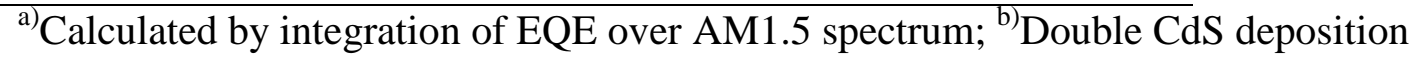




\section{WILEY-VCH}
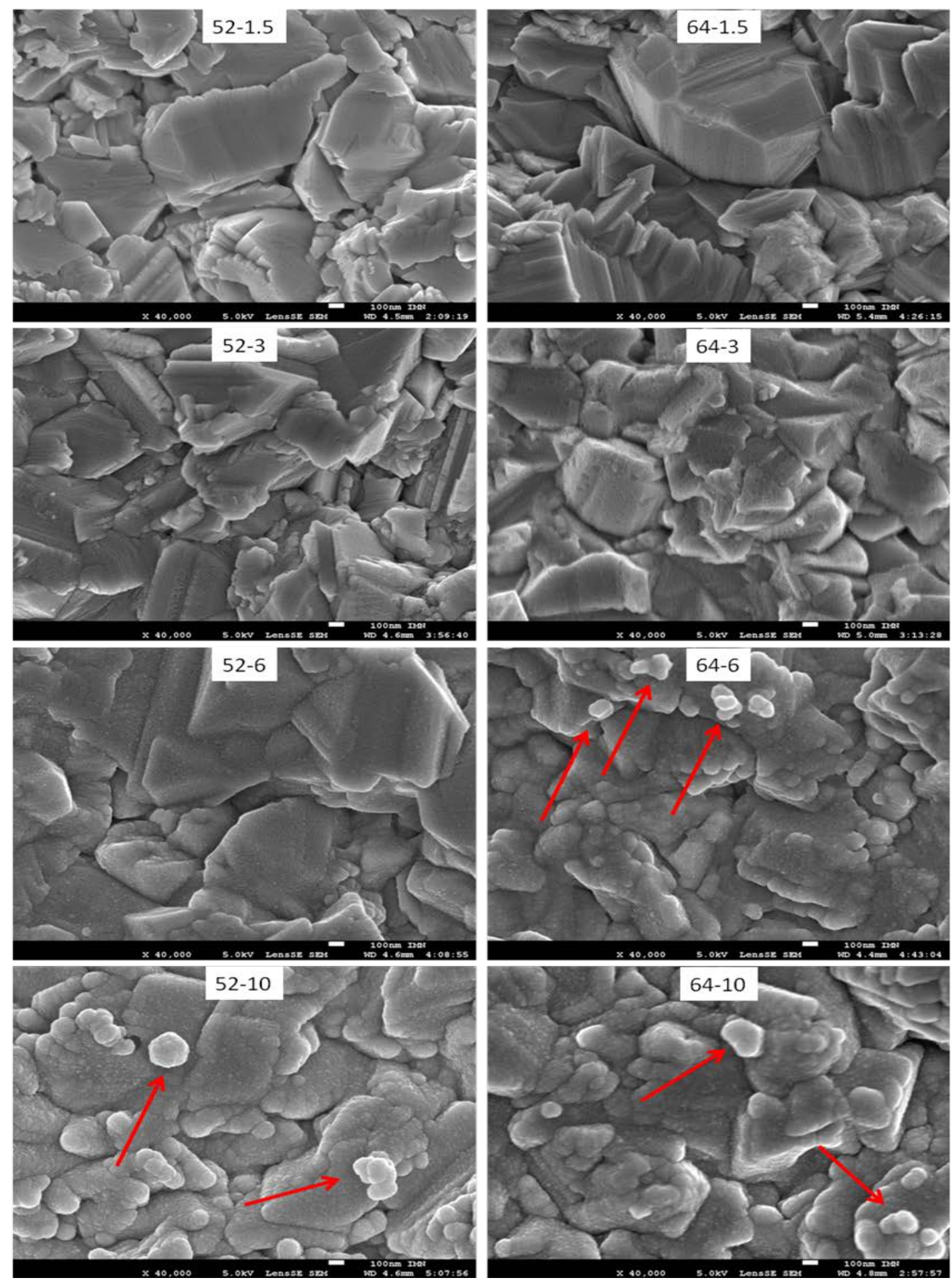

Figure 9. SEM images of CZGSe/CdS after 1.5,3,6 and 10 minutes of CdS deposition at 52 and $64^{\circ} \mathrm{C}$. Some examples of clusters are pointed out by arrows. High resolution and additional images are provided in supporting informations. 


\section{WILEY-VCH}

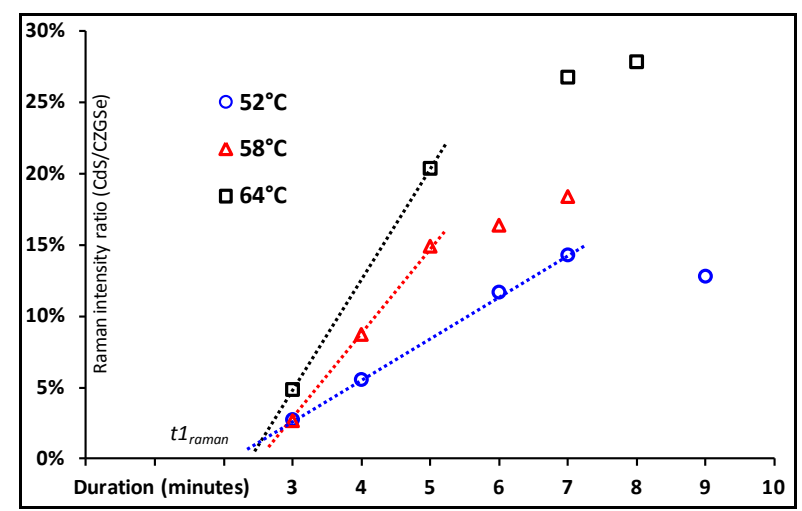

Figure 10: CdS/kesterite Raman peaks intensity ratio as a function of deposition duration at different deposition temperatures $\left(52 ; 58\right.$ and $\left.64^{\circ} \mathrm{C}\right)$. Dashed lines are eye guide which represent the constant growth rate during the ion-ion deposition stage

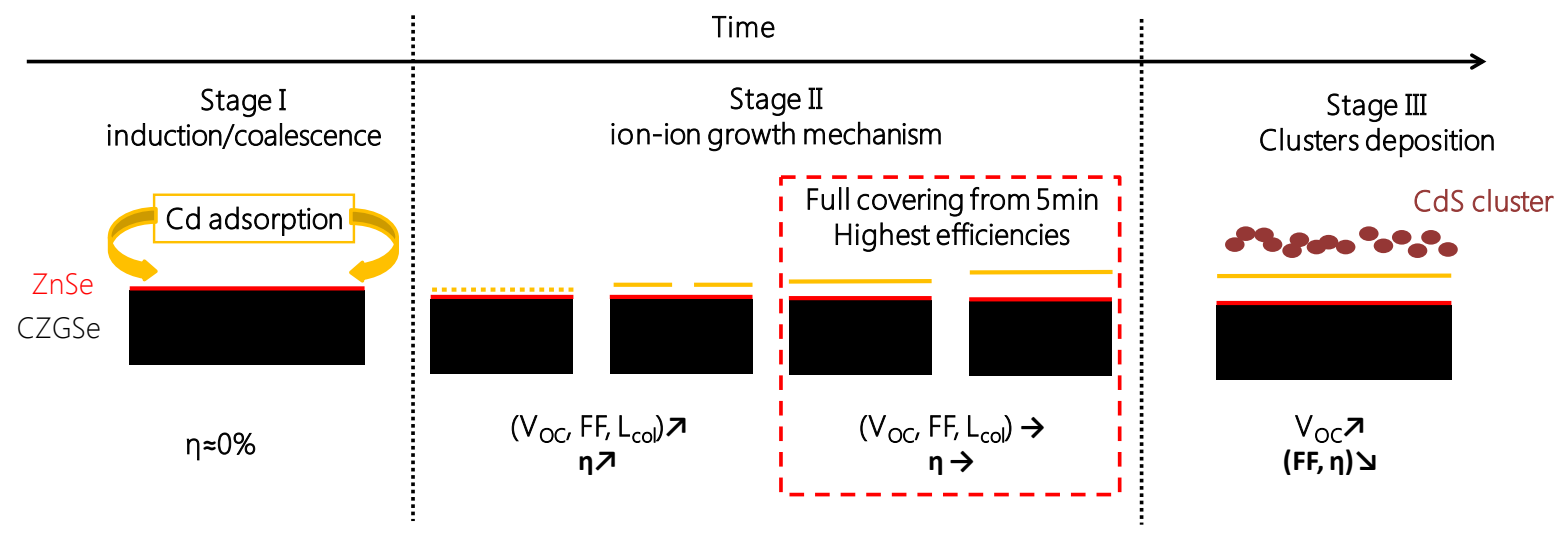

Figure 11. Schematic description of the three regime deposition of CdS and impact on solar cells
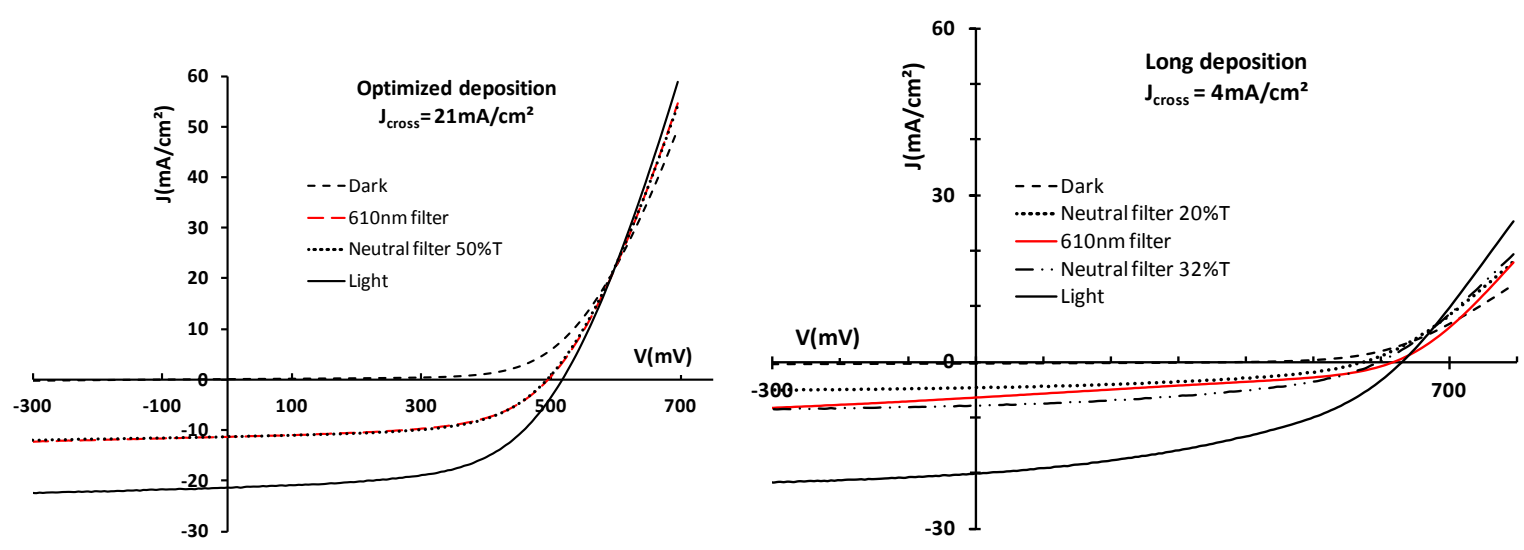

Figure 11. JV characteristics under various illuminations of solar cells with optimized and long CdS deposition 


\section{WILEY-VCH}
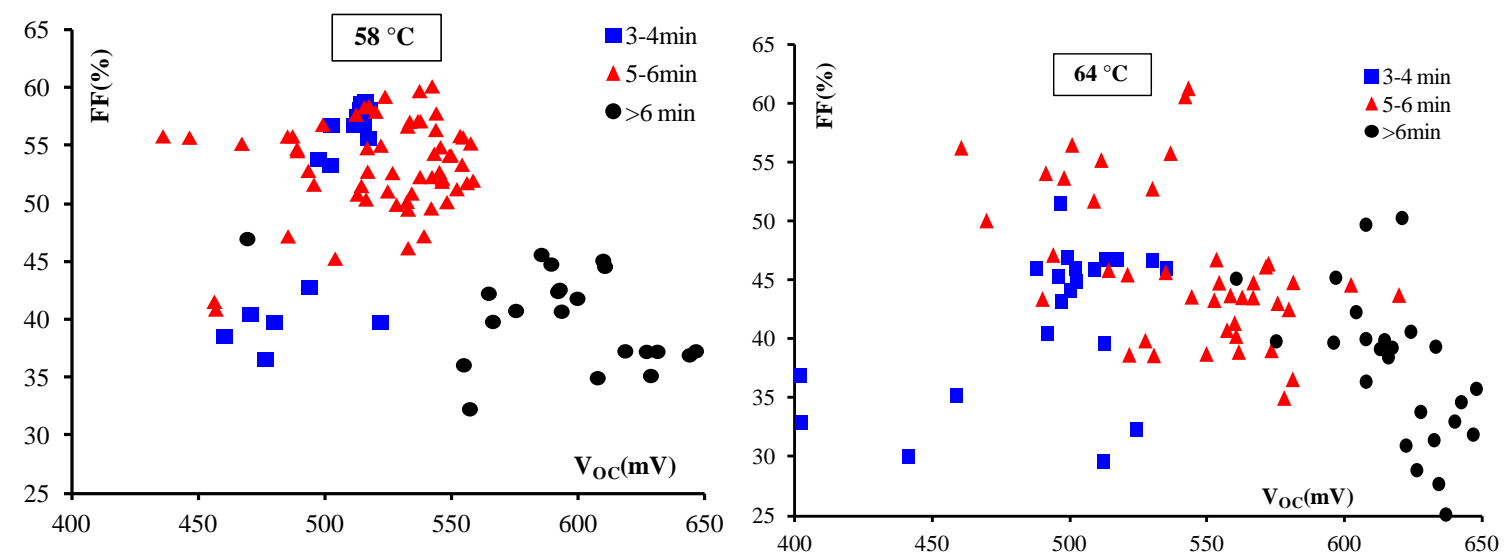

Figure 12. FF vs $\mathrm{V}_{\mathrm{OC}}$ map for $\mathrm{CdS}$ deposition at 58 and $64^{\circ} \mathrm{C}$ during various durations. Each point represents an individual solar cell. 
Supporting information:

\section{1- CdS thickness evaluation thanks to Raman intensity ratio}

On figure SI1 are presented examples of Raman spectra recorded using a 514nm excitation wavelength on the absorber only and on solar with different CdS thicknesses. As CdS is almost transparent at this wavelength (according to IQE-see figure 8 and figure 9 on the main manuscript), and CZGSe absorber considered as infinite (thickness of $1.5 \mu \mathrm{m}$ and complete $514 \mathrm{~nm}$ photons absorption for $\approx 100 \mathrm{~nm}$ ), intensity ratio of CdS/CZGSe Raman signal is considered as proportional to CdS thickness.

Fit with Lorentzian lines is then performed with 5 components for CZGSe (position typically $172 / 176 / 204 / 268 / 282 \mathrm{~cm}^{-1}$ ), one for CdS (typically $300 \mathrm{~cm}^{-1}$ ), and an additional line of very low intensity at $\approx 250 \mathrm{~cm}^{-1}$. The origin of the latter is not completely clear, as it corresponds to the same position as ZnSe main peak but is observed even on ZnSe-free sample (the absence of ZnSe being evaluated on Raman spectra with $458 \mathrm{~nm}$ wavelength-which is few tens of time more sensitive to ZnSe traces, see main manuscript figure 3). Then, it is likely that a CZGSe has a Raman line at $250 \mathrm{~cm}^{-1}$, with a very low intensity.

An example of such fit is provided on Figure SI-2. The intensity ratios are calculated as the area of the CdS line $\left(300 \mathrm{~cm}^{-1}\right)$, over the sum of areas of CZGSe lines at 172/176 and $204 \mathrm{~cm}^{-1}$. On each sample, 5 spectra are recorded and calculated ratios are averaged.

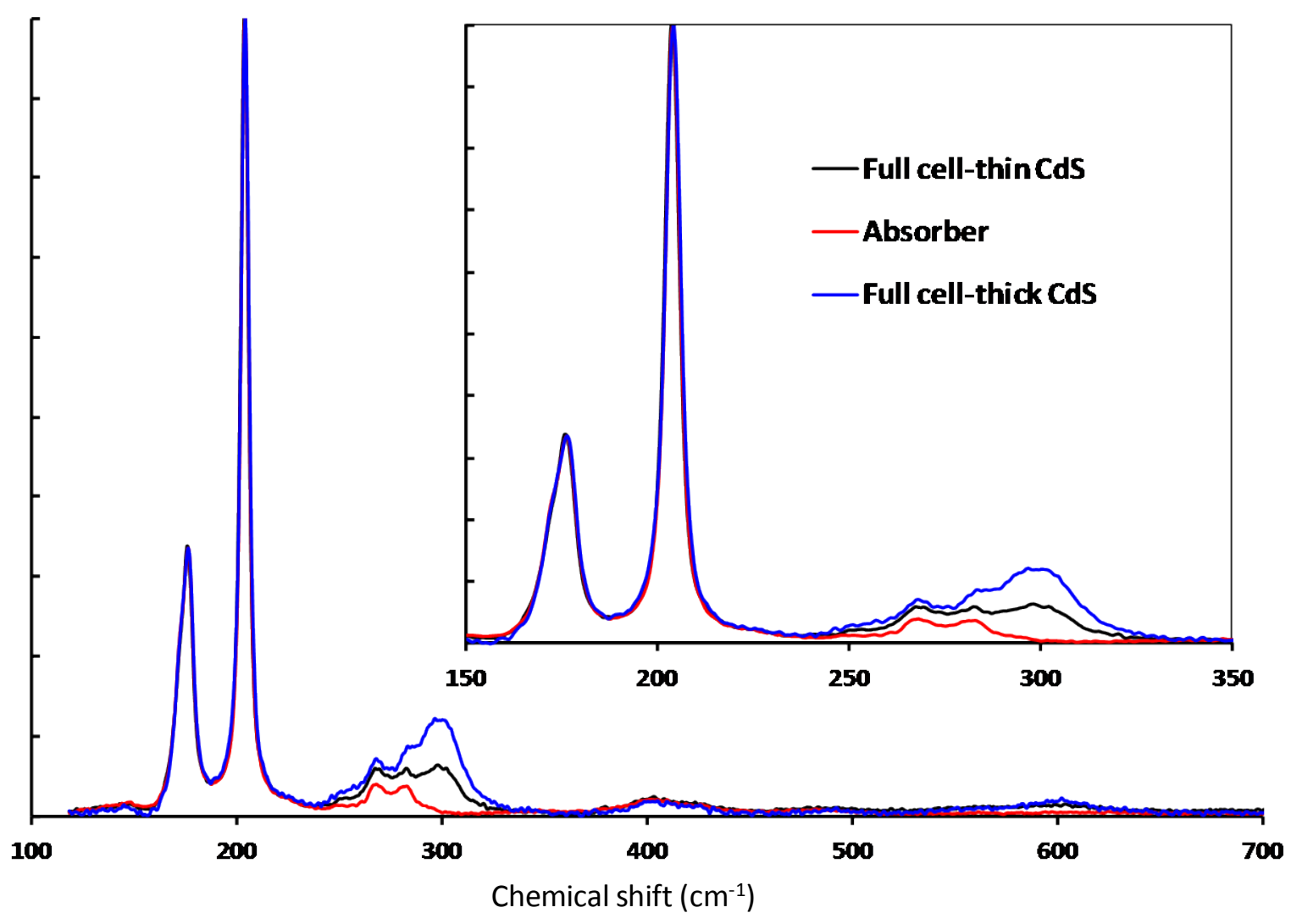

Figure SI-1 


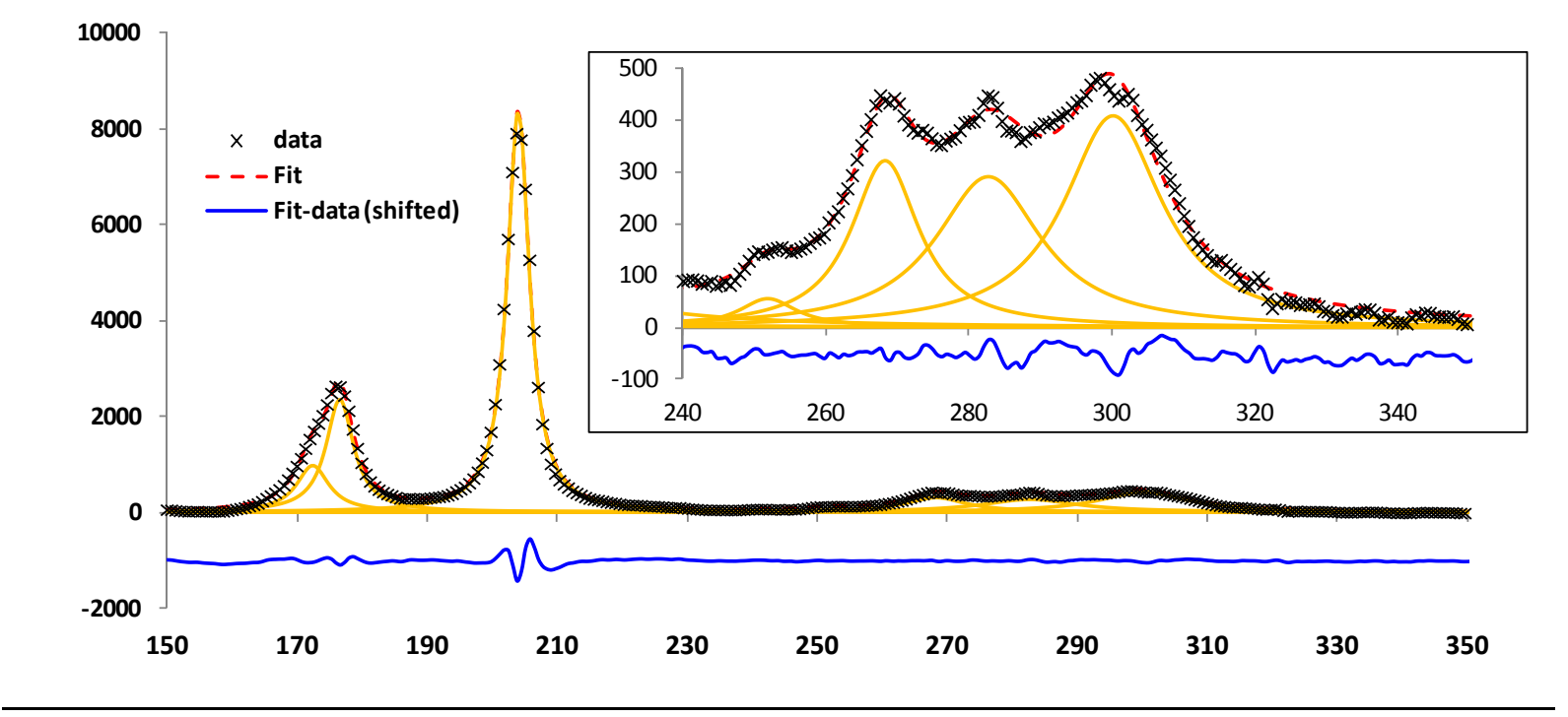

Figure SI-2

2- $\quad \underline{X R D}$ and presence of $\mathrm{ZnSe}$

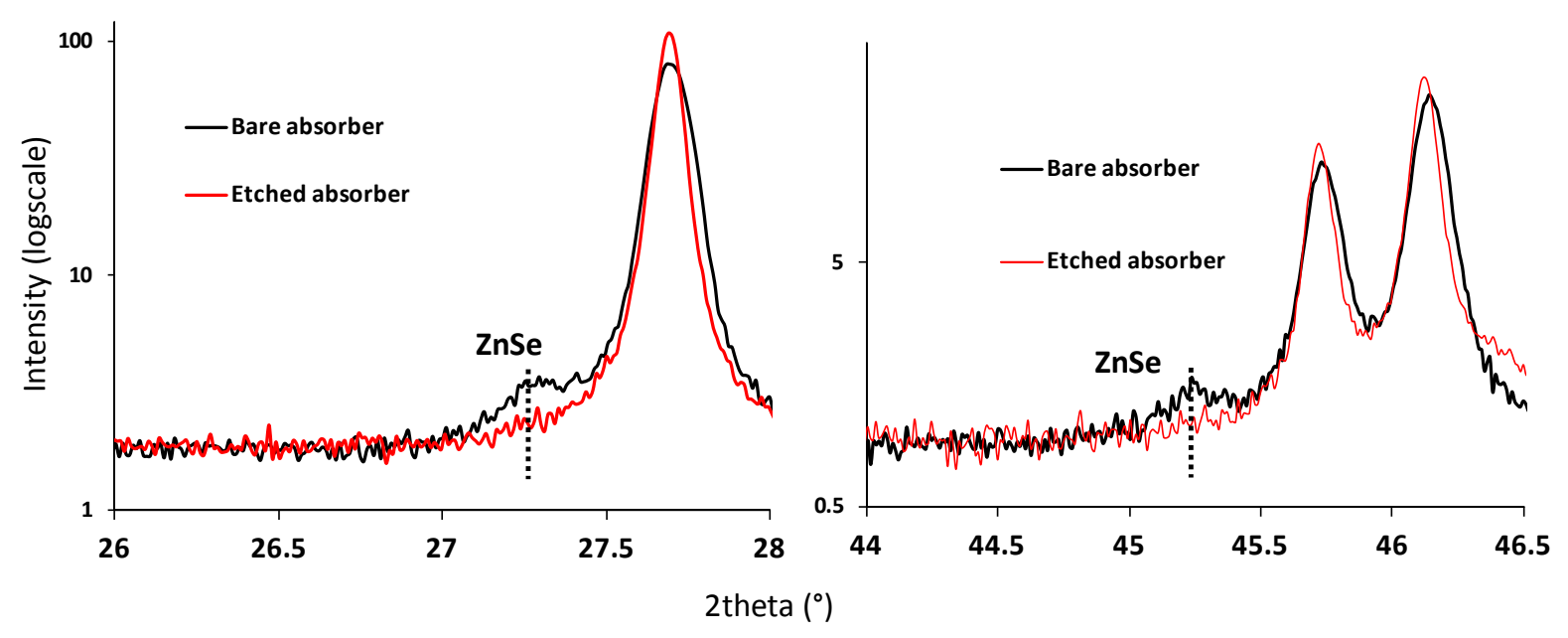

Figure SI-3

The presence of $\mathrm{ZnSe}$ in a very low amount is clear on bare absorber. But after $\mathrm{HCl}$ etching, no trace of $\mathrm{ZnSe}$ is detected anymore.

\section{3- Raman and start of CdS formation : 458 vs $514 \mathrm{~nm}$}

Some deposition is clearly observed on SEM images for short deposition - even from 1 minute. But no supplementary peak is observed on Raman spectra recorded with a $514 \mathrm{~nm}$ for depositions shorter than 3minutes - especially, no peak at 300 or $600 \mathrm{~cm}^{-1}$ (characteristic of CdS) are observed (Figure SI-4a). As the $300 \mathrm{~cm}^{-1}$ peak is of low intensity for a $3 \mathrm{~min}$ deposition, we cannot definitively determine if the absence of such peak for shorter deposition is due to an absence of CdS or because is amount is below the detection limit. Then, to reduce the detection threshold of $\mathrm{CdS}$, we performed 
Raman spectroscopy with a 458nm Laser excitation. Spectra are plot on figure SI-4b (performed on same sample as for the SI-4a): one can clearly observe the intensity of the $300 \mathrm{~cm}^{-1}$ peak to be far higher than the detection limit for a 3 minutes deposition, but that there is no any trace of such peak for a 1 minute deposition. Then, we conclude that the material observed on SEM images at the early stage of deposition is not CdS.

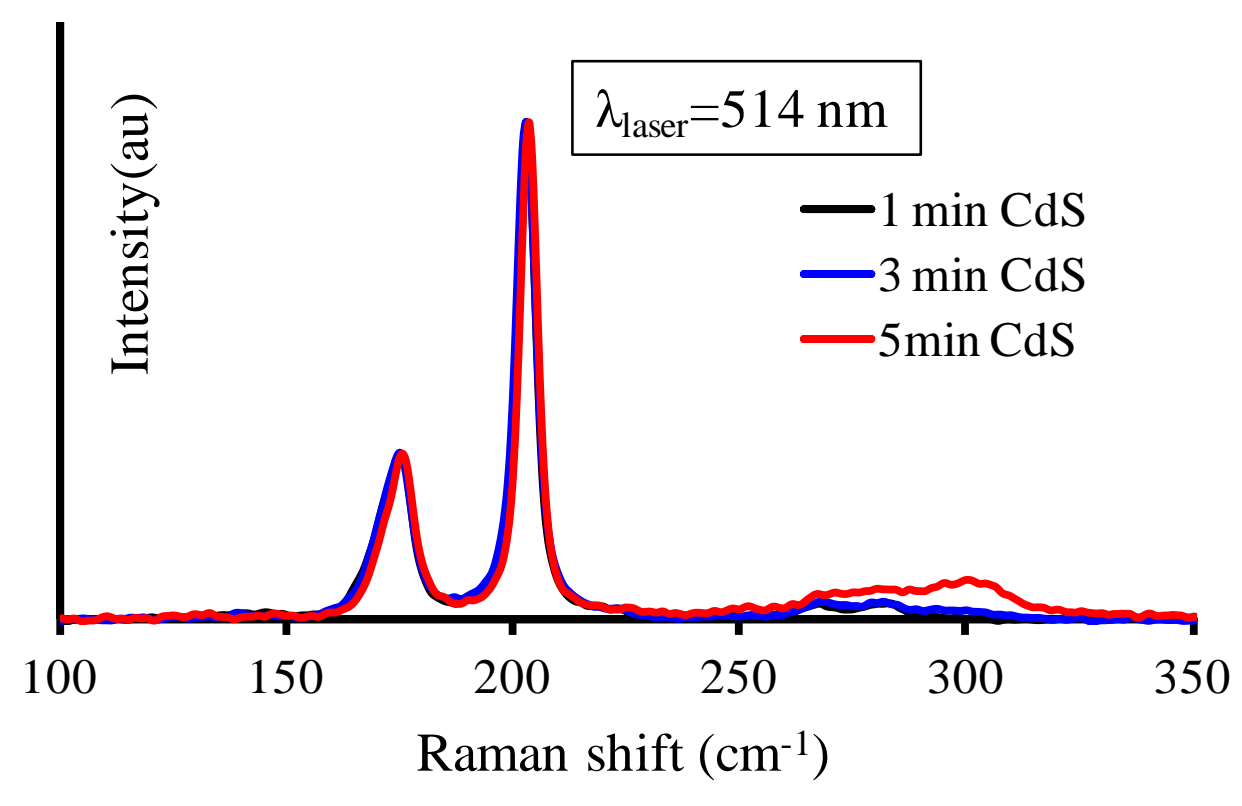

Figure SI-4a

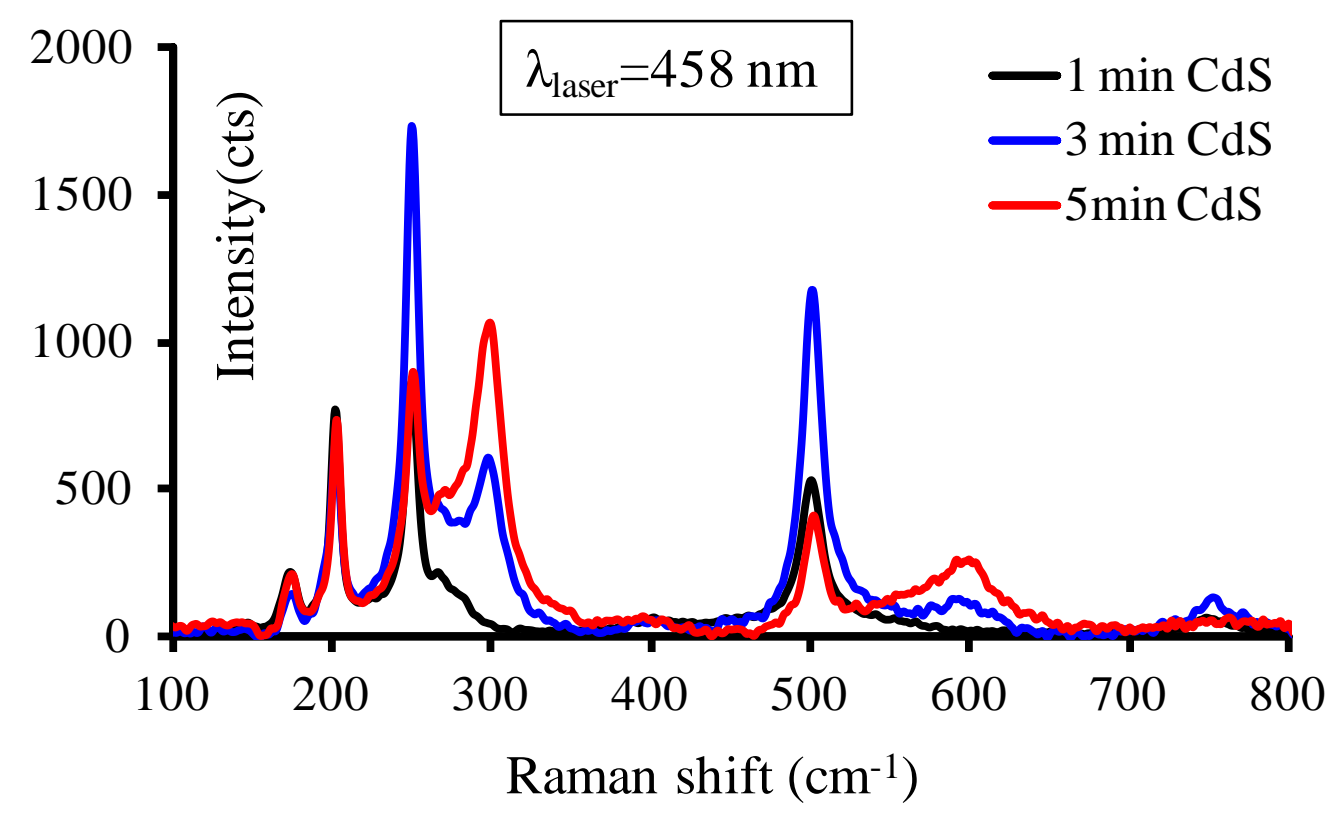

Figure SI-4b 


\section{4- Nature of the clusters observed for long CdS deposition}

For long CdS deposition, we clearly observe the deposition of hundred $\mathrm{nm}$ scale clusters of material (see figure 9 on manuscript and figure SIxx below). When such clusters are visible on SEM, one can observe yellow area of similar dimensions under the optical microscope of the Raman (see figure SI5). Then, Raman spectra have been recorded centred on those yellow area and immediately next (laser spot is of few $\mu \mathrm{m}$, then too much to record only on the yellow spot). Intensity of the 300 and $600 \mathrm{~cm}^{-1}$ peak characteristic of $\mathrm{CdS}$ are enhanced by orders of magnitude, which reveals the yellow spots to be CdS material (Fig SI-6).

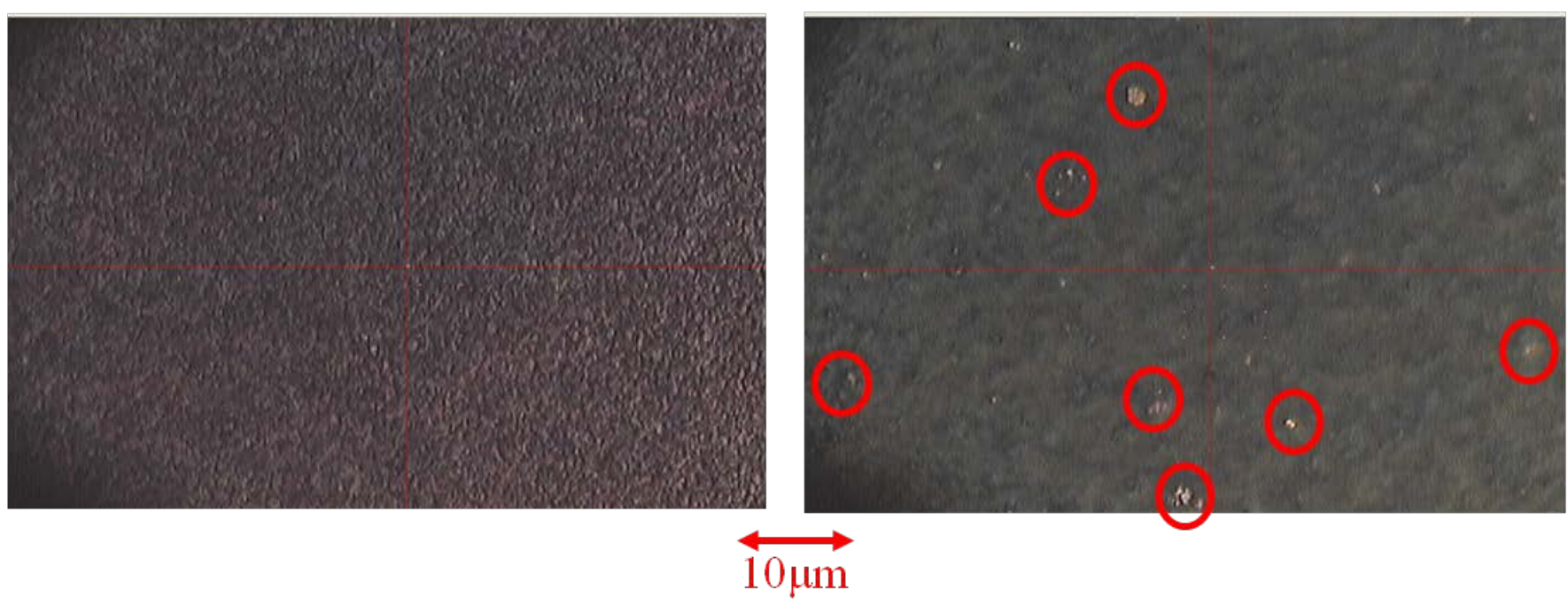

Figure SI-5 : Optical image of solar cells through Raman microscope.

Left: $5 \mathrm{~min}$ CdS deposition, right: 9 min CdS deposition (yellow clusters are surrounded in red)

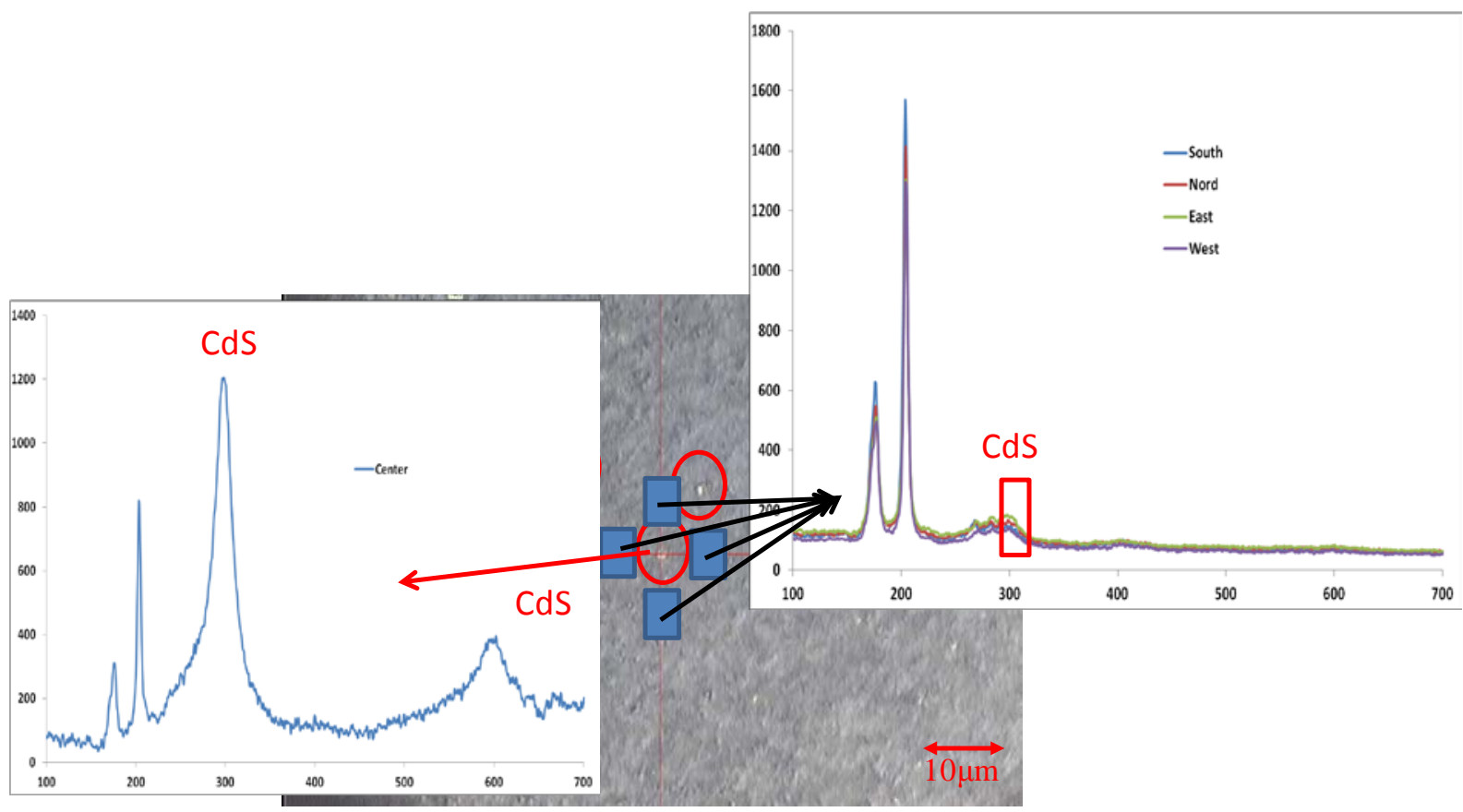

Figure SI-6 : Raman spectra recorded on and next to a cluster (514nm laser excitation)

At left: Raman spectra center on the cluster is dominated by CdS peaks, at right: the CdS peak intensity is low on the 4 spots recorded just around the cluster. 
5- SEM images, labelling $\left(T^{\circ}-t\right) T^{\circ}$ is the CdS deposition temperature in Celsius, $t$ is the CdS deposition duration in minutes

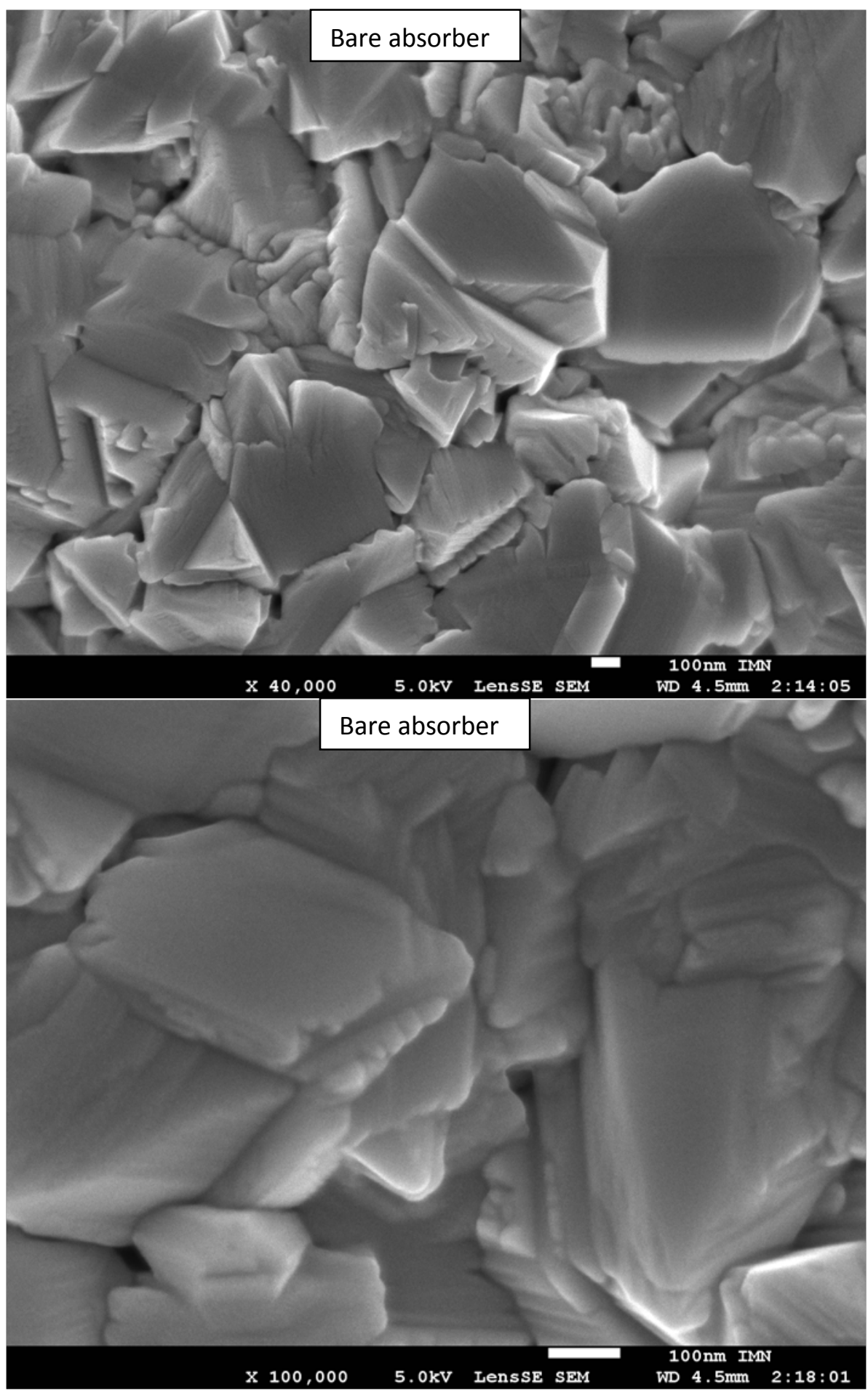




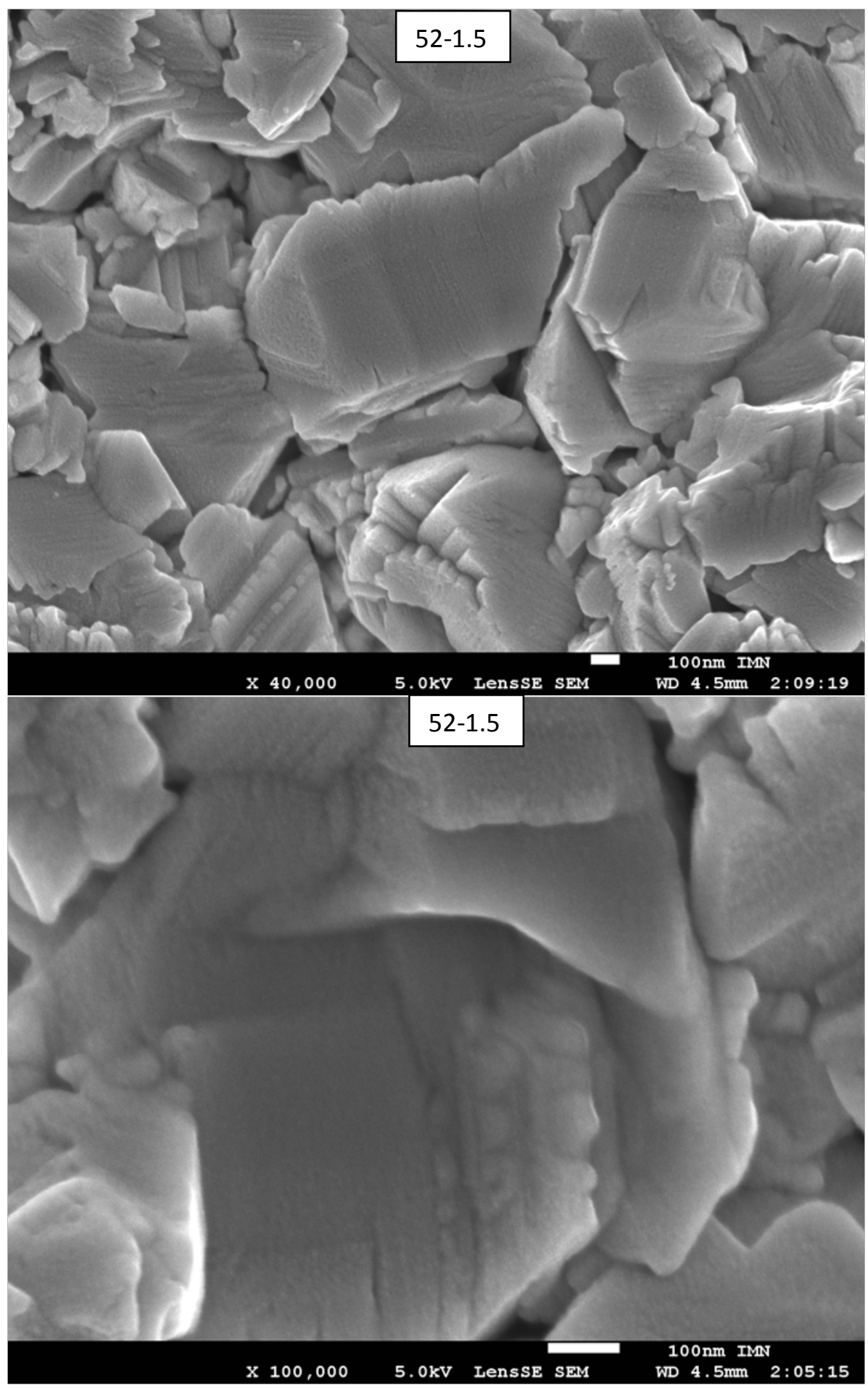




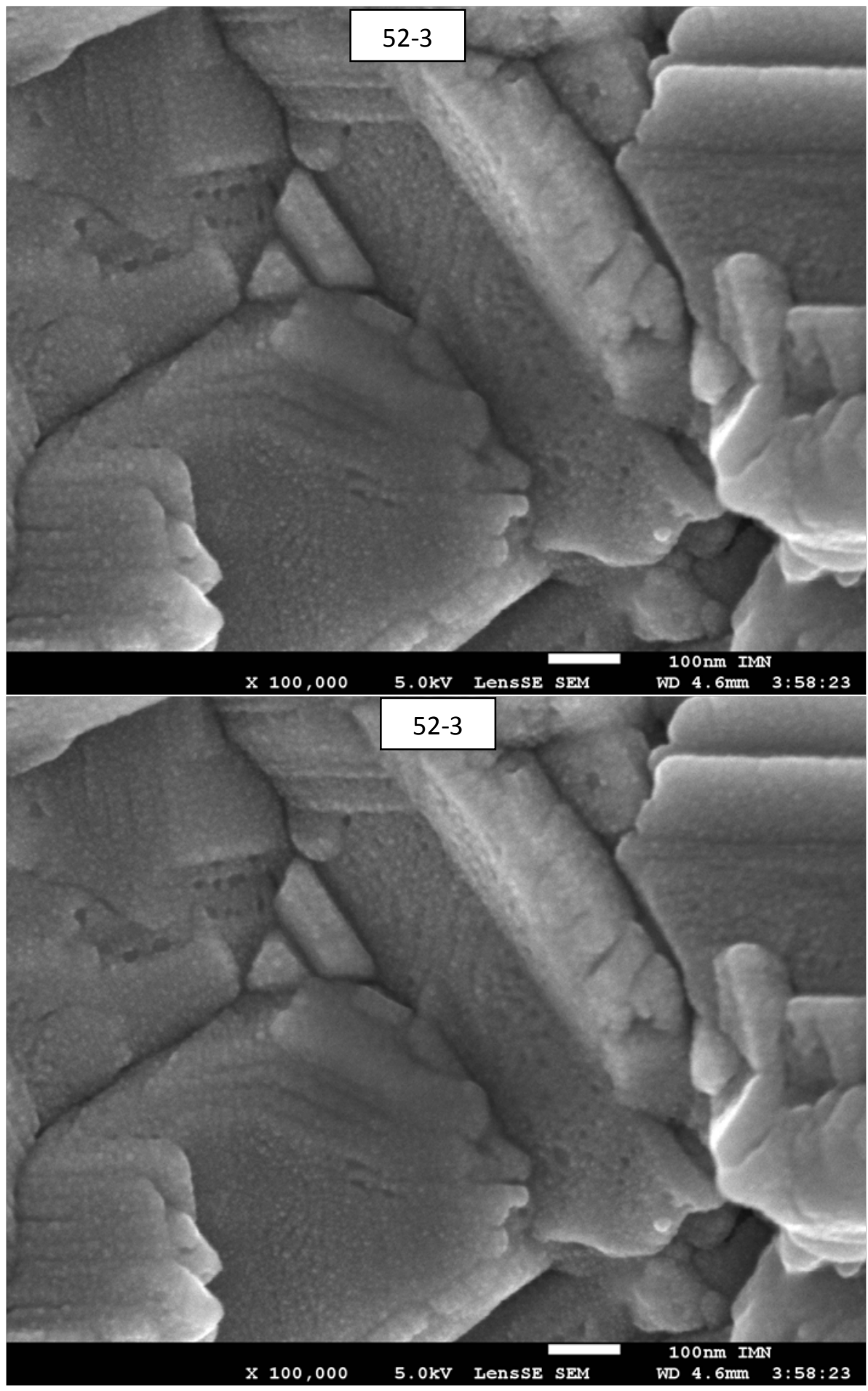




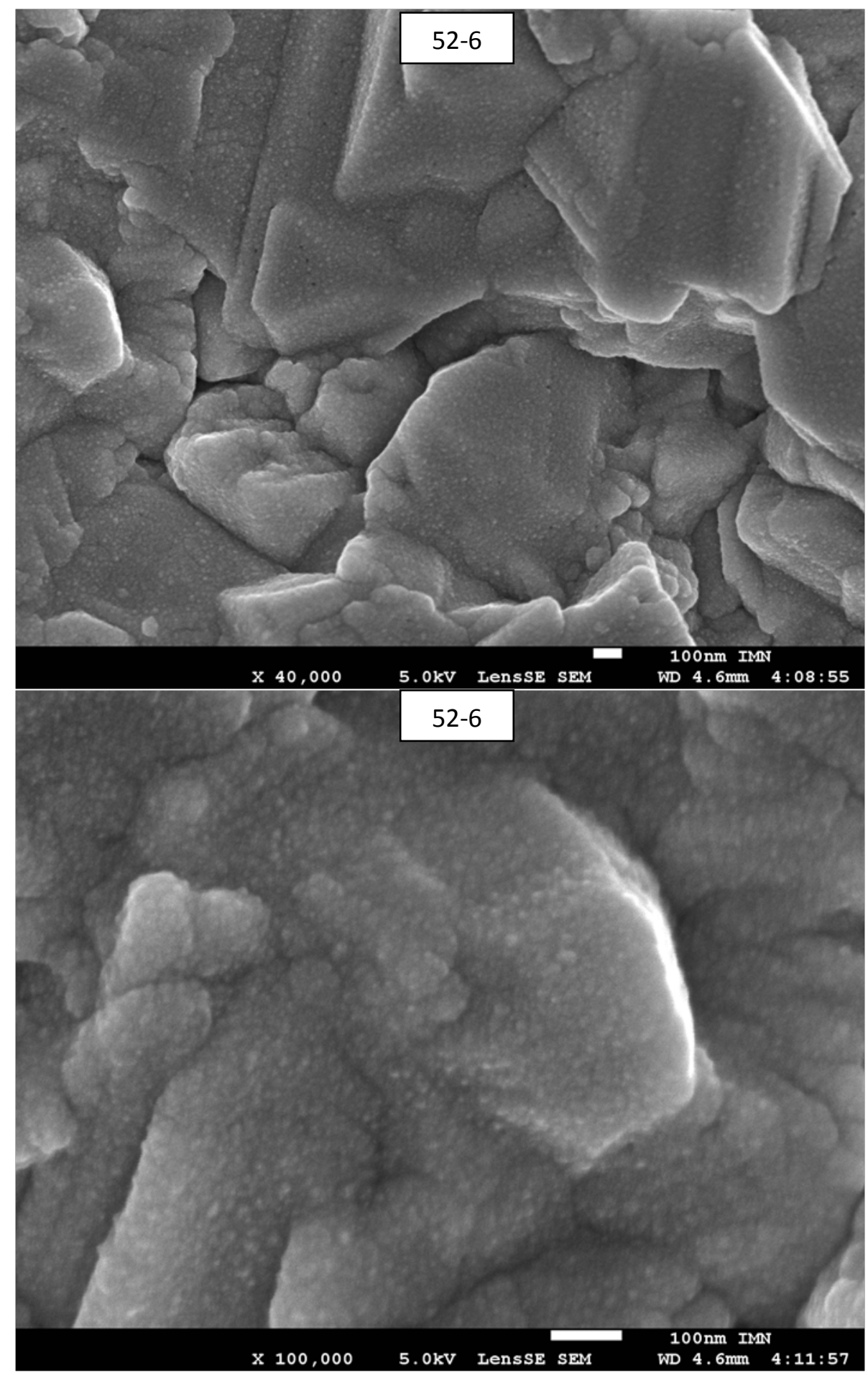




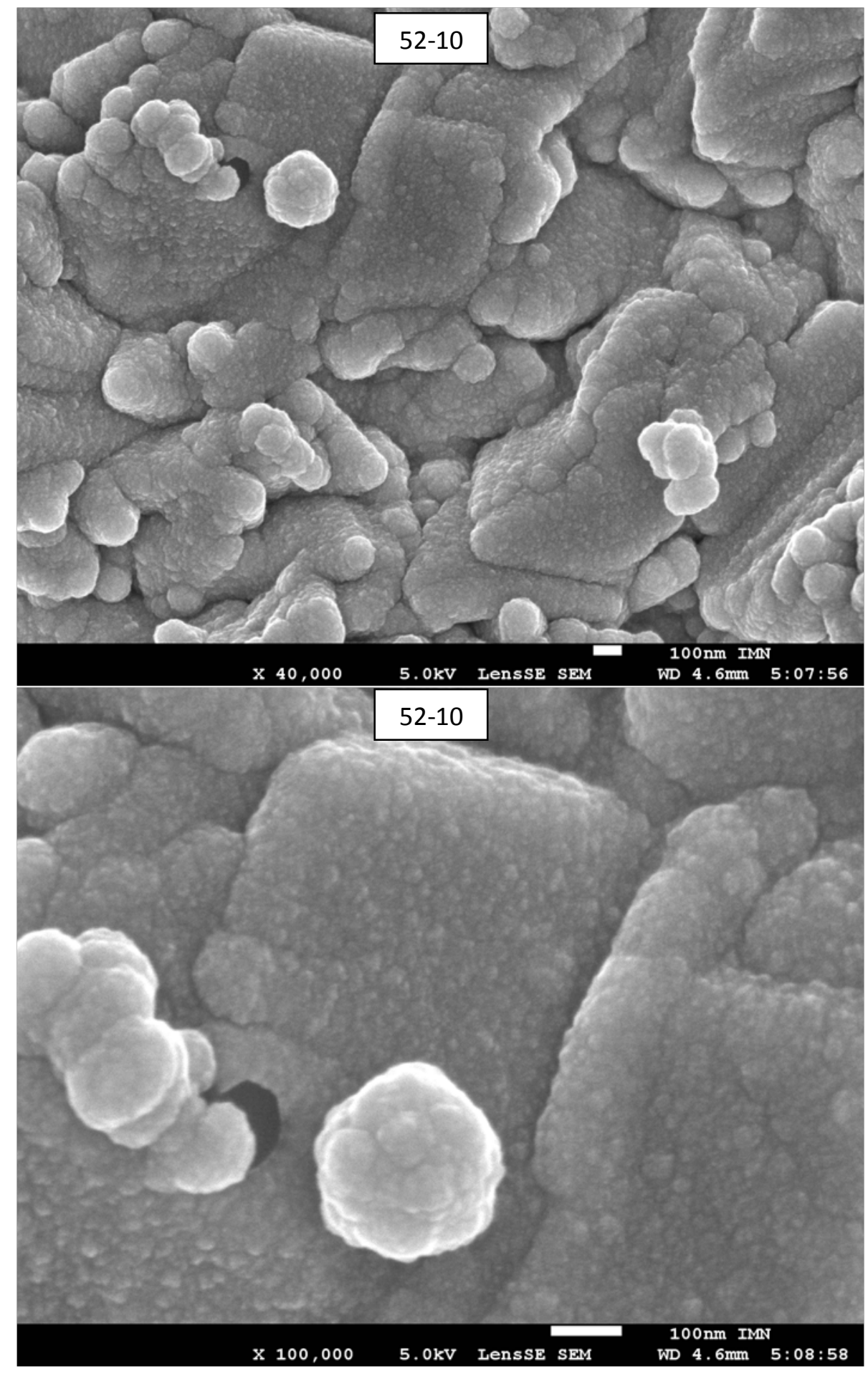




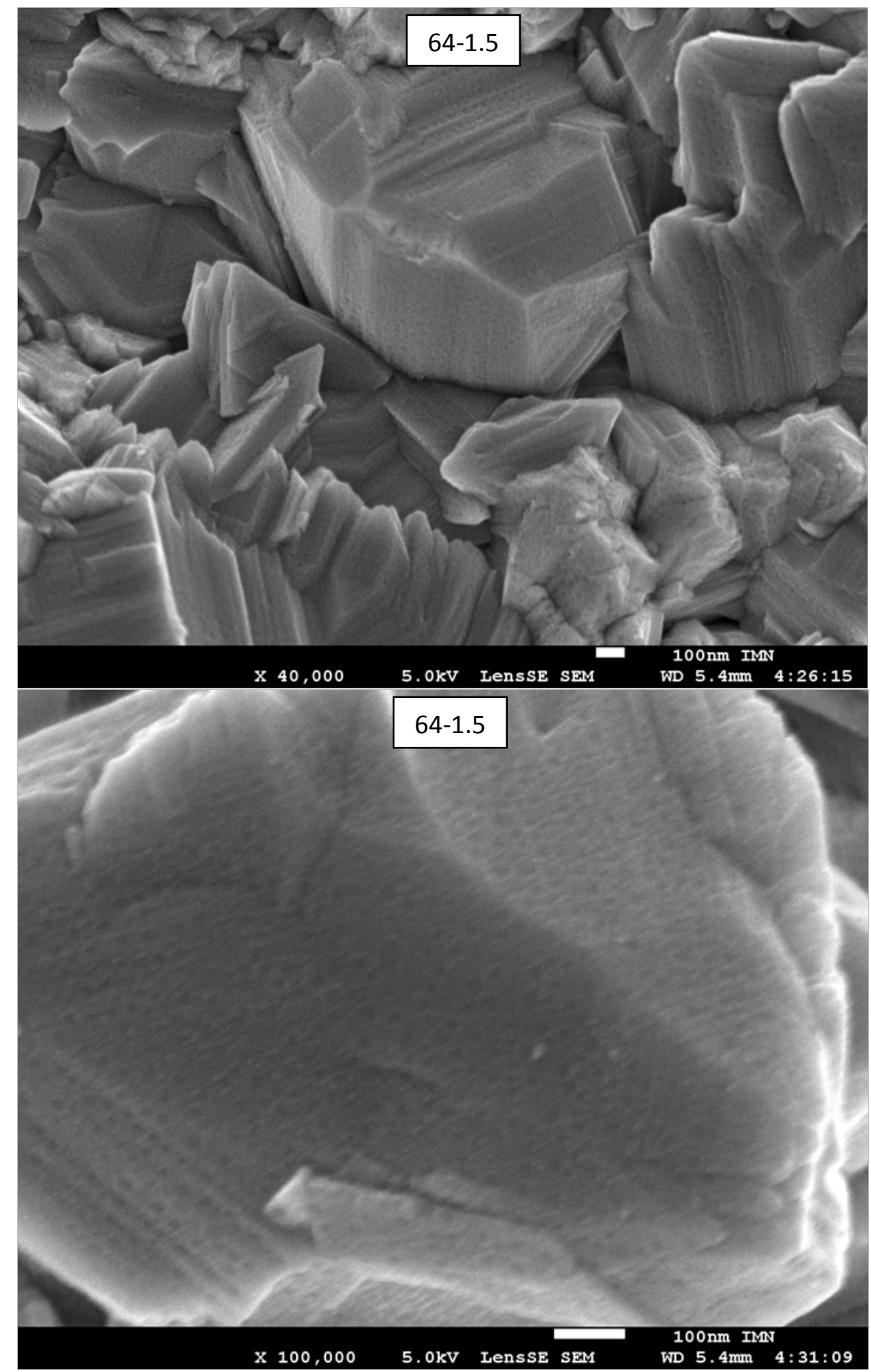




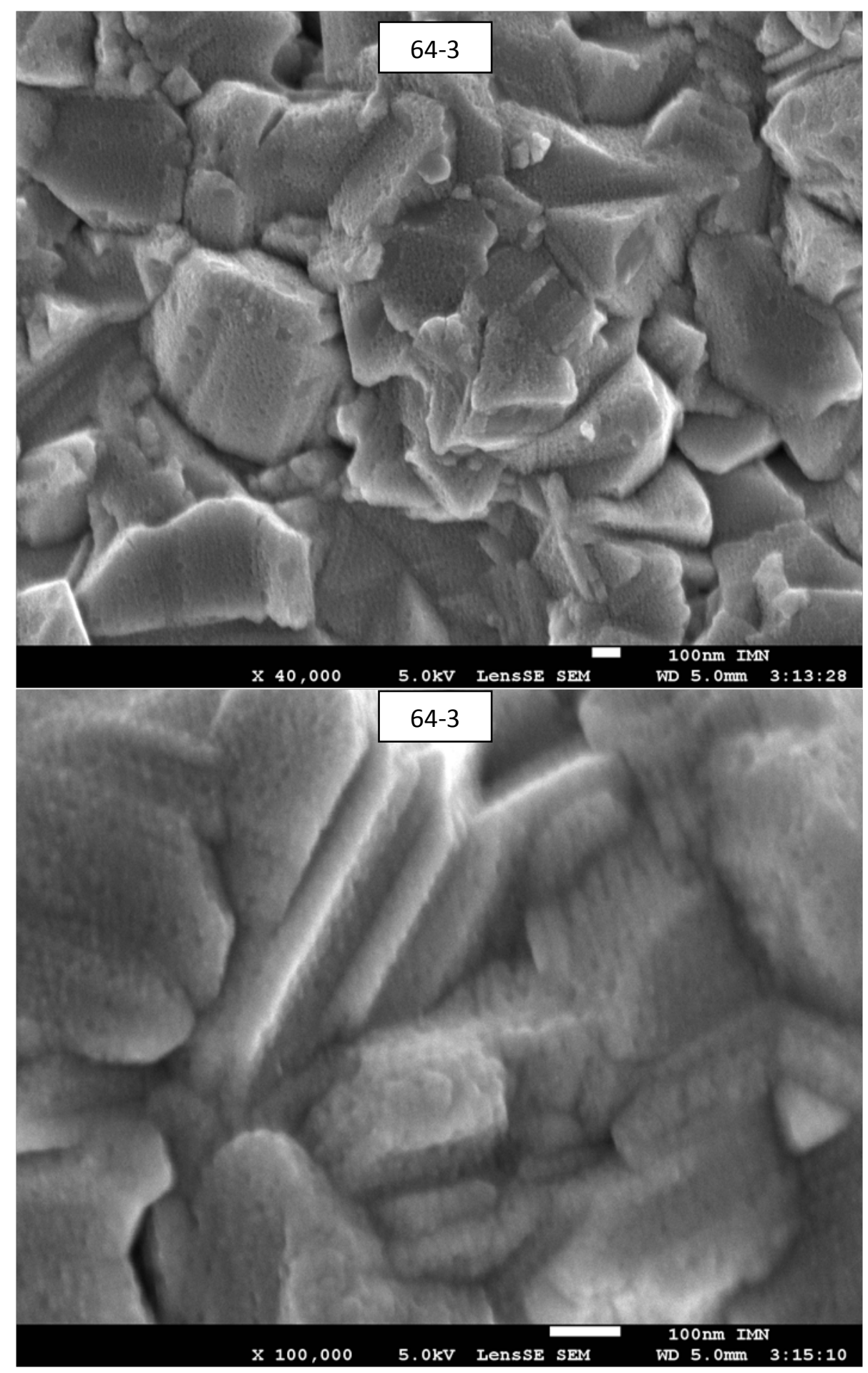




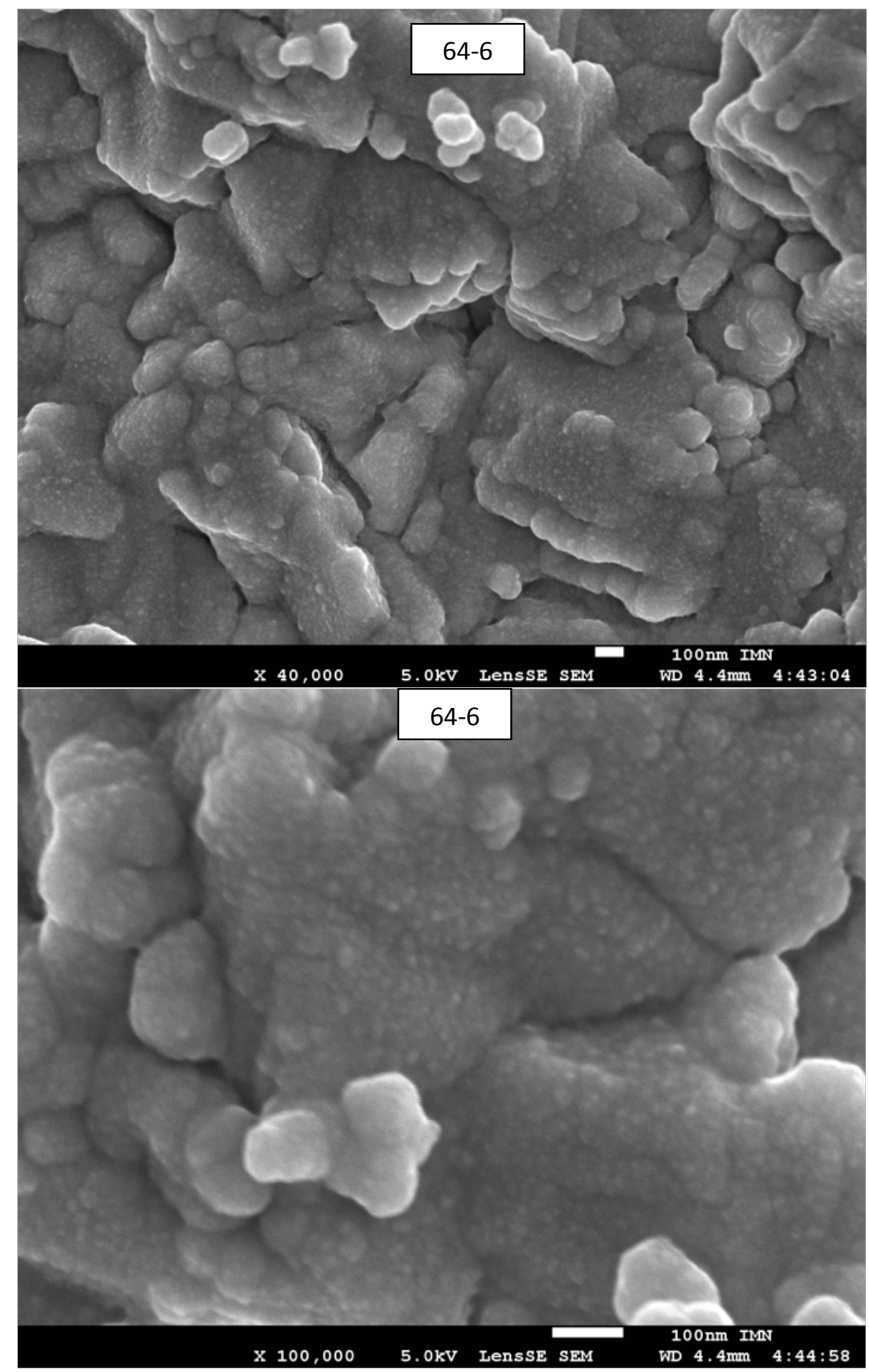




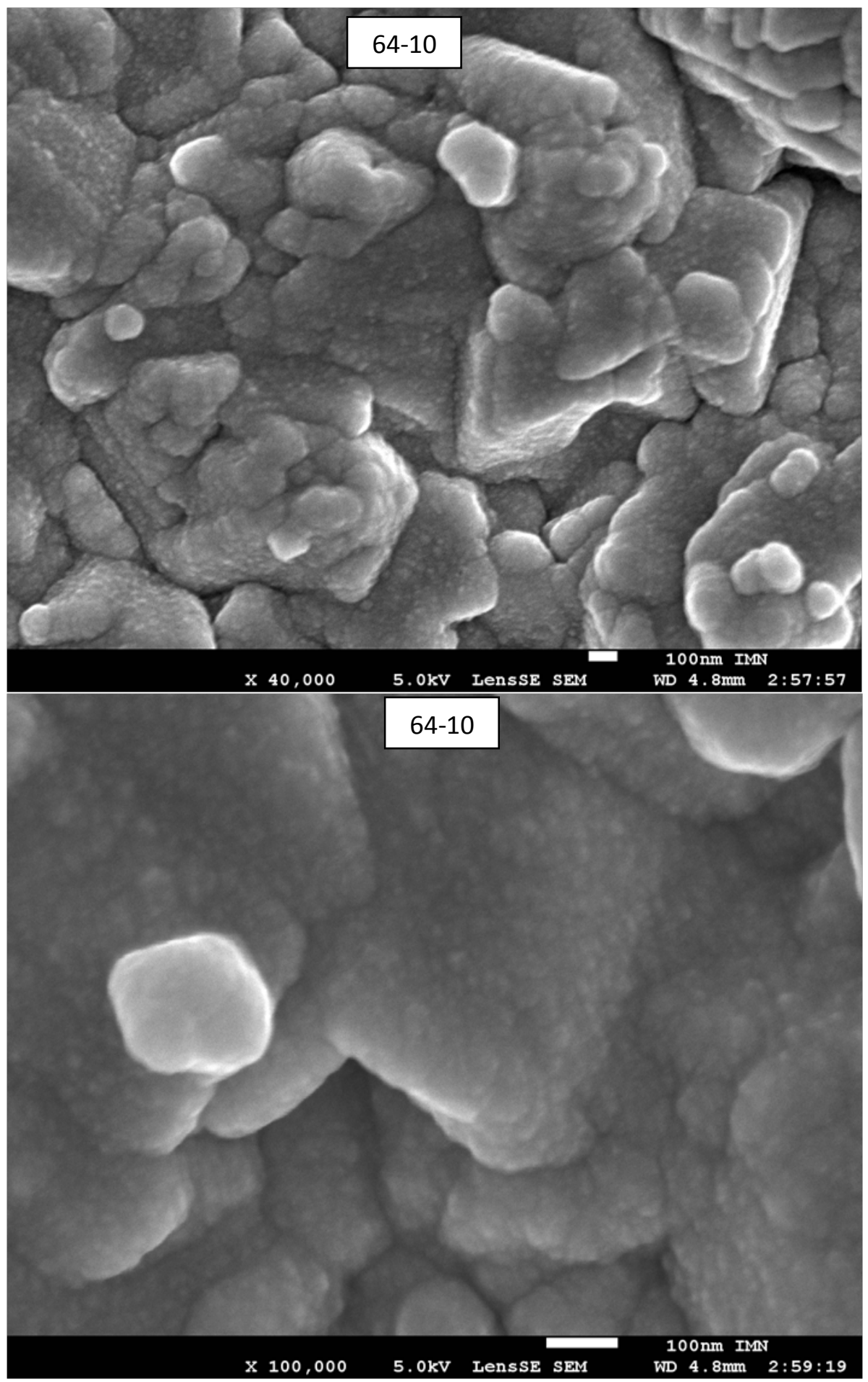

